Portland State University

PDXScholar

Dissertations and Theses

Dissertations and Theses

8-27-1974

\title{
Alumina-Catalyzed Cope Rearrangement
}

Paul Jhy-Shing Wang

Portland State University

Follow this and additional works at: https://pdxscholar.library.pdx.edu/open_access_etds

Part of the Chemistry Commons

Let us know how access to this document benefits you.

\section{Recommended Citation}

Wang, Paul Jhy-Shing, "Alumina-Catalyzed Cope Rearrangement" (1974). Dissertations and Theses. Paper 2405.

https://doi.org/10.15760/etd.2402

This Thesis is brought to you for free and open access. It has been accepted for inclusion in Dissertations and Theses by an authorized administrator of PDXScholar. Please contact us if we can make this document more accessible: pdxscholar@pdx.edu. 
AN ABSTRACT OF THE THESIS OF Paul Jhy-Shing Wang for the Master of Science in Chemistry presented August 27, 1974.

Title: Alumina-Catalyzed Cope Rearrangement.

APPROVED BY MEMPERS OF THE THESIS COMMITTEE:

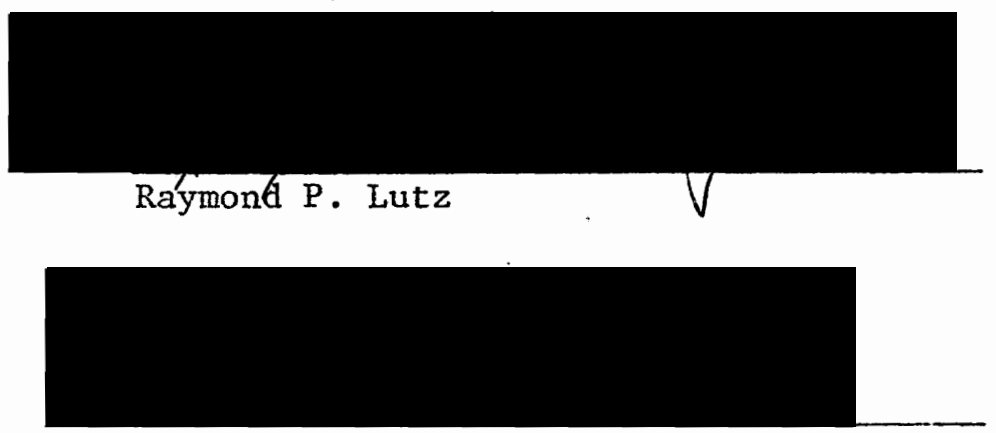

Norman C. Rose

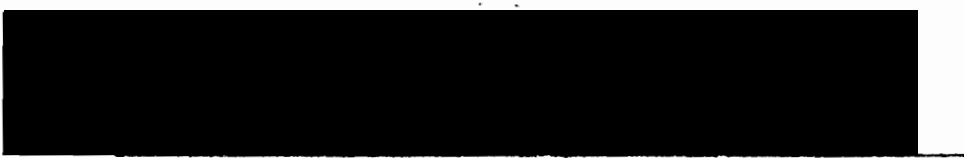

Edward M. Perdue

The alumina-catalyzed Cope rearrangements of meso- and d1-3,4diphenylhexa-1,5-diene were examined in detail, following up a prelimInary observation by $\mathrm{H}$. Berg at Portland State University. Commercial column-chromatography grade alumina was employed, and was further activated before use by heating at $650-700^{\circ}$ for four hours.

Using a ratio of $20 \mathrm{mg}$ of $\mathrm{d1}-3,4$-diphenylhexa-1,5 diene to $1 \mathrm{~g}$ of alumina in heptane, the Cope rearrangement was complete within 15 minutes at room temperature to give exclusively trans, trans-1,6-diphenylhexa-1,5-diene. This was identified by melting point, infrared 
spectroscopy and vapor phase chromatography.

The catalyzed rearrangement of meso-3,4-diphenylhexa-1,5-diene was run using the same diene to alumina ratio. It was found that $31 \%$ of the meso-diene was converted to cis,trans- and trans,trans-1,6-diphenylhexa-1,5-diene at room temperature in four hours. Product isomerization appeared to take place; the initial ratio of cis,trans-diene to trans,trans-diene was estimated to be 73:27. Another run was carried out at $60^{\circ}$, where the problem of isomerization of cis,trans-diene to trans, trans-diene was more pronounced. The rearrangement gave cis, trans-diene and trans,trans-diene in a ratio of 58:42, as estimated by extrapolation of the product ratio to zero time. Approximately $95 \%$ of meso-diene had reacted in one hour at this temperature. The extent of conversion of meso-diene was calculated by quantitative infrared spectroscopy, and the isomeric distribution of products was determined by vapor phase chromatography. .

The product distribution in the alumina-catalyzed rearrangements parallels that of the thermal Cope rearrangement, where d1-diene gives exclusively trans,trans-diene at $80^{\circ}$ with a half-life of eight hours and meso-diene gives $63 \%$ cis,trans-diene and $27 \%$ trans, trans-diene at $120^{\circ}$ with a half-life of 15 hours. 
PAUL JHY-SHING WANG

\title{
A thesis submitted in partial fulfillment of the requirements for the degree of
}

\author{
MASTER OF SCIENCE \\ in \\ CHEMISTRY
}

\section{Portland State University 1974}


TO THE OFFICE OF GRADUATE STUDIES:

The members of the Committee approve the thesis of

PAUL JHY-SHING WANG presented August 27, 1974.

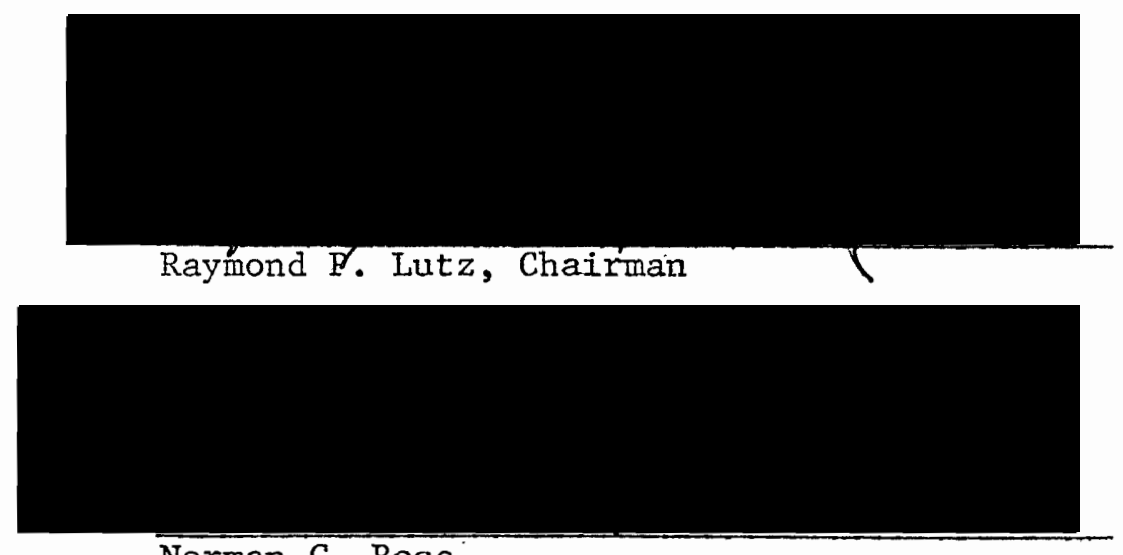

Norman C. Rose

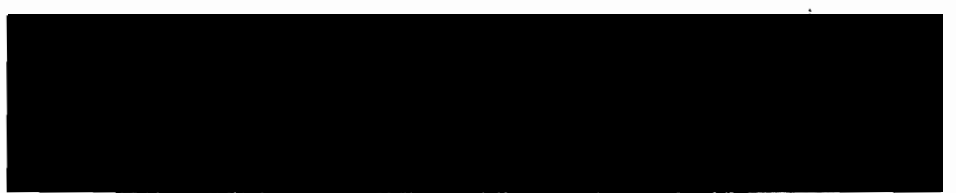

Edward M. Perdue

APPROVED :

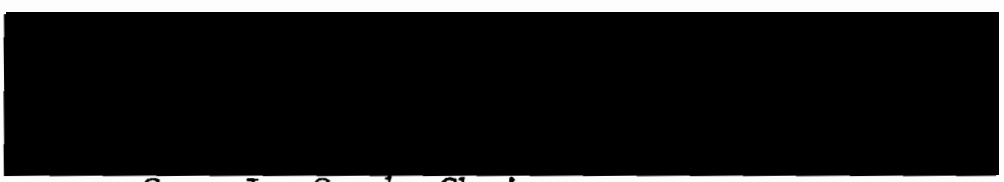

Gary L. Gard, Chairman

Department of Chemistry

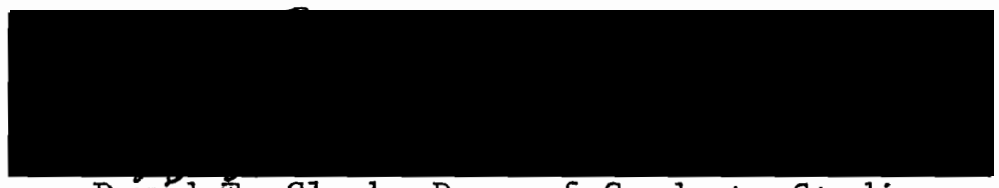

David T. Clark, Dean of Graduate Studies 


\section{ACKNOWLEDGEMENTS}

I am forever grateful to $\mathrm{Dr}$. Raymond $\mathrm{P}$. Lutz for his patient and persistent guidance throughout this research project. During the past two years, his friendship and helpful attitude gave me confidence in the process of my research. In addition thanks are extended to $\mathrm{Dr}$. Dennis Barr= and Mr. Patrick Green who allowed me to use apparatus and manuIactured ampules required for the experimental work.

This thesis is dedicated to

my mother 
TABLE OF CONTENTS

PAGE

ACKCONLEDGMENTS . . . . . . . . . . . . . . . . . . . iii

IIST OE TABLES . . . . . . . . . . . . . . . . . . . . . v v

IIST OF FIGURES . . . . . . . . . . . . . . . . . . . . . . vii

IMRODUCTION • : • • . . . . . . . . . . . . . . . . . 1

RESUIT LND DISCUSSION

I. PREPARATION OE STARTING MATERIALS . . . . . . . . . 9

IT. ALTMINA-CATALYZED REARRANGEMENT OF d1-DIENE . . . . . . 10

III. ALLMTNA-CATALYZED REARRANGEMENT OF meso-DIENE . . . . . 15

GENERAI IABORATORY PROCEDURES AND INSTRUMENTATION . . . . . . . . . 24

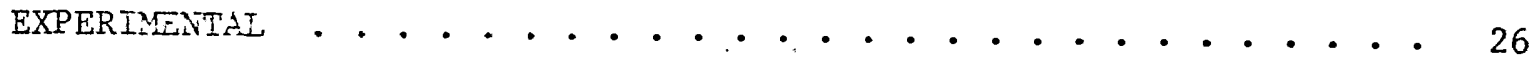

BIBLIOGRAPHY • • . . . . . . . . . . . . . . . 43 


\section{LIST OF TABLES}

I Activation Parameters for Selected Cope Rearrangement . . . . 2

II Summary of Extent of Catalyzed Rearrangement and Product Distribution of meso-Diene at Room Temperature ( 1 hour). . . 16

II Summary of Extent of Catalyzed Rearrangement and Product Distribution of meso-Diene at room temperature ( 4 hours). .

IY Summary of Extent of Catalyzed. Rearrangement and Product Distribution of meso-Diene at $60^{\circ}$........... 


\section{LIST OF FIGURES}

FIGURES

Page

1 Possible transition states for rearrangement of a meso-3,4-disubstituted hexa-1,5-diene . . . . . . . .

2 Synthetic route for preparing meso- and d1-3,4-dipheny1hexa-1,5-diene as illustrated for the meso isomer . . . . 9

3a IR spectrum of authentic d1-3,4-diphenylhexa-1,5-diene. . 12

32. IR spectrum of authentic meso-3,4-diphenylhexa-1, 5-diene . . . . . . . . . . . . . . . . .

$4 a$ IR spectrum of authentic trans,trans-1,6-diphenylhexa-1, 5-diene....................

45 IR spectrum of alunina-catalyzed rearrangement product of d1-3,4-dipherylhexa-1,5-diene . . . . . . . .

5 Vapor phase chromatogram of crude product from the aluminacat $=1 y z e d$ rearrangement of d1-3,4-diphenylhexa-1, 5-diene....................

6 Gas cinromatogral of meso-3,4-diphenylhexa-1,5-diene rearranged on activated alumina (diene:alumina, $20 \mathrm{mg}: 2 \mathrm{~g}$ ) at $60^{\circ}$, for 10 hours . . . . . . . . . .

7 Gas chromatogram of meso-3,4-diphenylhexa-1,5-diene re-. arranged on aciivated alumina (diene:alumina, $20 \mathrm{mg}: 1 \mathrm{~g}$ ) at room temperature for 60 minutes . . . . . . . .

8 Product distribution for the alumina-catalyzed Cope rearrangement of meso-3,4-diphenylhexa-1,5-diene at room temperature . . . . . . . . . . . . . .

9 Gas chromatogram of meso-3,4-diphenylhexa-1,5-diene rearranged on alumina (diene:alumina, $20 \mathrm{mg}: 1 \mathrm{~g}$ ) at $60^{\circ}$ for 15 minutes . . . . . . . . . . . . .

10 Product distribution for the alumina-catalyzed Cope rearrangement of meso-3,4-diphenylhexa-1,5-diene at $60^{\circ}$. . . . . . . . . . . . . . . 
vii

FIGURES

Page

11 Thin layer chromatograms of meso- and d1-3,4-dipheny1hexa-1,5-diene, trans-1,4-diphenylhexa-1,5-diene, 1,6diphenylhexa-1,5-dienes on silica gel impregnated with silver nitrate . . . . . . . . . . . . . . . . 

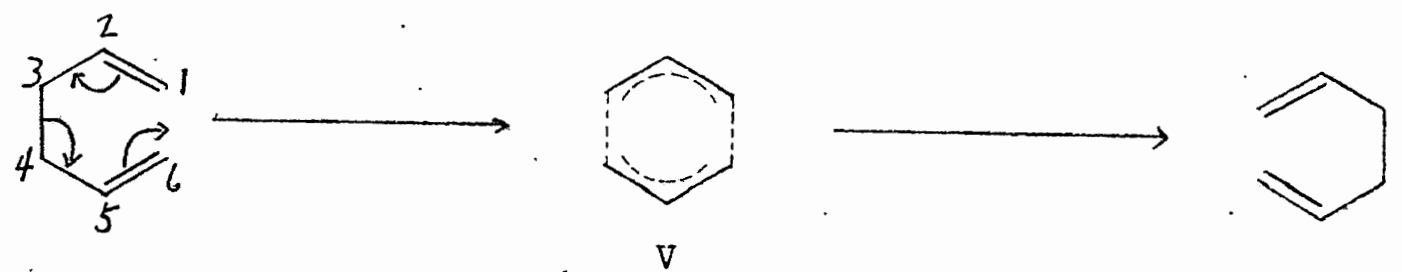

absence of intermolecular crossing (3), insensitivity to solvent changes, the adherence of the reaction to a first order rate law, and the inversion of allylic groups. Consistent also with a cyclic transition state are the relatively low enthalpies of activation, and negative volumes and entropies of activation, which are observed experimentally (4). (See Table I.)

TABLE I

ACTIVATION PARAMETERS FOR SELECTED

COPE REARRANGEMENTS

\section{COMPOUND}

1,1-Dideuteriohexa-1,5-diene

meso-3,4-Dimethylhexa-1,5-diene

d1-3,4-Dimethylhexa-1,5-diene

d1-3,4-Dimethylhexa-1,5-diene

d1-3,4-Diphenylhexa-1,5-diene

Diethyl allylisopropenyl malonate
$\Delta \mathrm{H}^{\neq} \mathrm{kcal} / \mathrm{mole}$

33.5

33.1

$35.2^{\mathrm{a}}$

$35.3^{b}$

23.8

28.4

$$
\Delta S^{\frac{1}{F}} \text { eu }
$$

$-13.8$

$-11.2$

$-5.9$

$-10.1$

$-12.9$

$-13.5$
Ref.

5

6

6

6

4

7

\footnotetext{
$\mathrm{a}_{\text {For rearrangement to trans, trans-octa-2,6-diene }}$

$b_{\text {For rearrangement to cis,cis-octa-2,6-diene }}$
}

Although electronegative groups such as $\mathrm{CN}$ and $\mathrm{CO}_{2} \mathrm{Et}$ at position 3 or 4 facilitate the rearrangement, this is probably due to their capacity for conjugation with the partially formed double bond in the 
transition state rather than their electronegative character. For when these polar groups are replaced by phenyl, the rearrangement goes about as easily (8). There is no doubt that the phenyl group, by its capacity for conjugation, reduces the activation energy of the reaction.

Doering and Roth (9) pointed out that an acyclic molecule possessIng a hexa-1,5-diene type structure has more than one possible six-nenbered cyclic transition state for the Cope rearrangement. Each is derived from a different conformation of the hexadiene skeletion (Eigure 1). The energetically preferred transition state of the Cope rearrengement was established by examining the product distribution of the rearrangements of meso- and d1-3,4-dimethylhexa-1,5-diene. The reso compound rearranged almost exclusively (99.7\%) to cis,trans-octe-2,6-diene. The remaining $0.3 \%$ was the trans,trans isomer and may have arisen from impurities in the starting material. The counterpart d1-diere yielded $90 \%$ trans,trans- and $10 \%$ cis,cis-octa-2,6-diene.

Doering's results may be rationalized by considering the rearrangement of the meso-dimethyl compound as illustrated in Fig. 1. OE tie tro possible transition states available, only the chair-like four-center type, VIa, leads to the major product, cis,trans-octa-2,6-diene. The sixcenter boat-like transition state, VIIa, leads to the isomeric trans,transdiene which, observed in trace amounts, may have resulted from resicual d1 isomer in the starting material. A similar analysis starting with the dl isomer (not shown in Fig. 1) indicates that the trans,trans and cis,cis-octa-2,6-dienes were generated via chair-like transition states. The reaction product expected through a six-center transition state, $\underline{\text { cis, }}$, trans-octa-2,6-diene, was not observed.

Doering concluded that the four-center geometry has the lower energy 

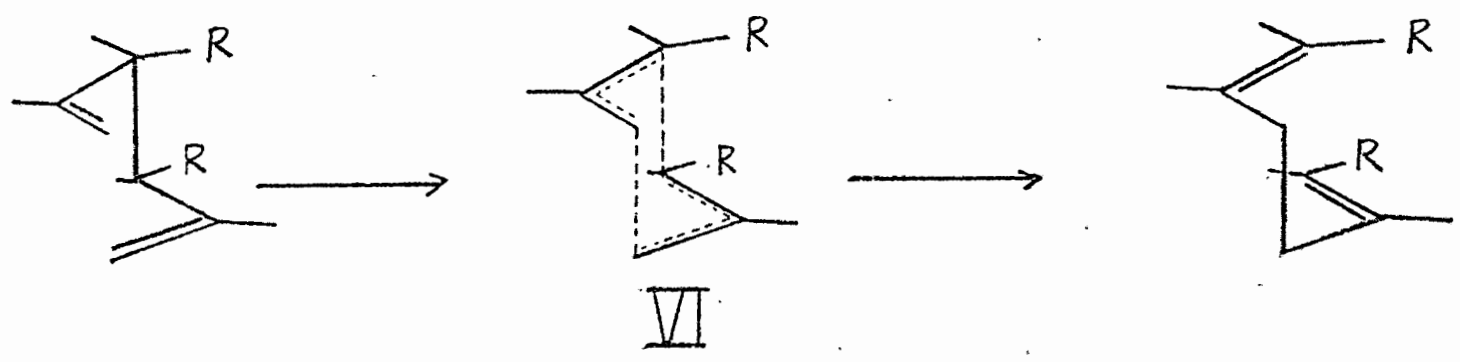

$$
\text { a, } \begin{aligned}
& \mathrm{R}=\mathrm{CH}_{3} \\
& \text { b, } \mathrm{R}=\mathrm{C}_{6} \mathrm{H}_{5}
\end{aligned}
$$
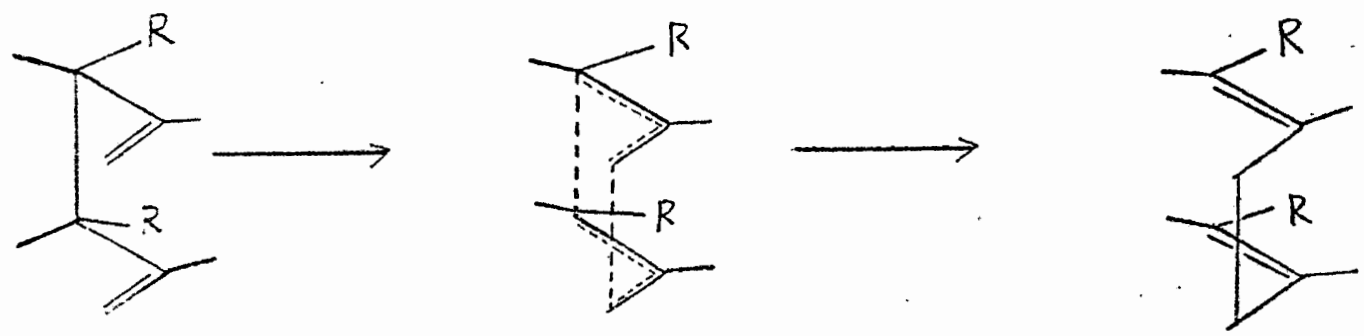

$$
\begin{aligned}
& \text { a, } \mathrm{R}=\mathrm{CH}_{3} \\
& \text { b, } \mathrm{R}=\mathrm{C}_{6} \mathrm{H}_{5}
\end{aligned}
$$

Figure 1. Possible transition states for rearrangement of a meso-3, 4-disubstituted hexa-1,5-diene. 
on the basis of the product distribution. The favored energy difference over the six-center conformation amounted to at least $5.7 \mathrm{kcal} / \mathrm{mole}(9)$. Although neither of the examples cited above underwent rearrangement through a six-center transition, state, several examples (10) are known where the reaction proceeds only through this mode due to steric barriers to rearrangement through the four-center transition state.

A number of years prior to Doering and Roth's work, Koch (11) had reported the preparation of meso-3,4-diphenylhexa-1,5-diene and claimed that it rearranged thermally to a $2: 3$ mixture of trans-1,4-diphenylhexa1,5-diene and trans,trans-1,6-diphenylhexa-1,5-diene. Based on the accepted cyclic mechanism of the Cope rearrangement as well as Doering and Roth's results, neither of these two products would be expected. A reinvestigation of the reaction by Lutz and co-workers (12) revealed that Koch had incorrectly identified the structure of one product. Actually the rearrangement (at $120^{\circ}$ ) gave $63 \%$ cis,trans- and $37 \%$ of trans,trans1,6-diphenylhexa-1,5-diene as kinetically controlled products. Evident1y both the four-centered (VIb) and the six-centered (VIIb) transition state were involved.

The contrasting behavior of the diphenyl derivative can be rationalized by taking account of the steric and electronic effects of phenyl groups on the transition state geometries. The generation of a cis double bond in the four-center configuration (VIII to IX) creates a steric interaction which forces the phenyl group out of coplanarity with the allyl group to which it is attached (geometries shown in Fig. 2). The non-coplanarity of the phenyl group reduces the energetically favorable electronic interaction during reaction, but it does not overcome the fundamental preference for the four-center transition state and most of the 
molecules rearrange by this route. However a significant fraction rearranges by the six-center route, which allows full coplanarity of phenyl substituents in the formation of the trans double bonds (X to XI).

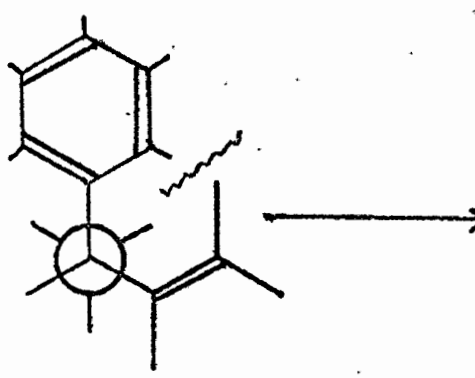

VIII

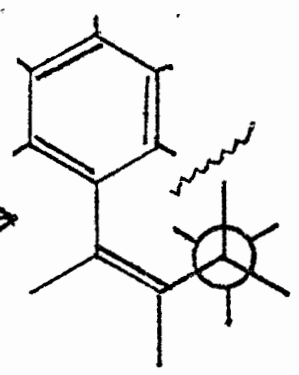

IX

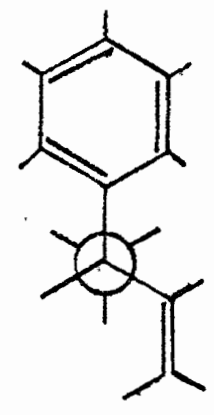

$\mathrm{X}$

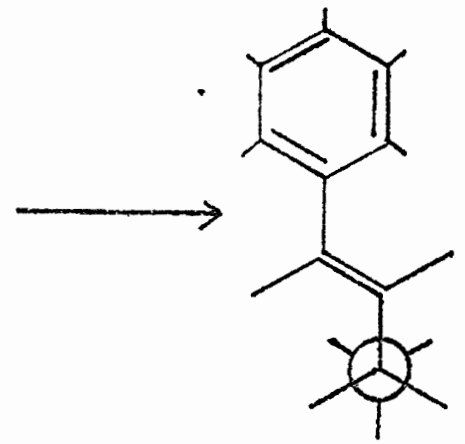

$X I$

Investigation was extended to the dI-3,4-diphenylhexa-1,5-diene, which rearranged exclusively to trans,trans-1,6-diphenylhexa-1,5-diene through a four-center transition state. The absence of the cis,cis isomer was attributed to the unfavorable steric and electronic effects discussed above.

In the course of studying the rearrangement kinetics of d1-3,4diphenylhexa-1,5-diene, Berg (4) attempted to purify a contaminated d1diene sample by column chromatography on very active neutral alumina (Woelm, grade super I). The completely unexpected observation was made that the dl-diene during chromatography rearranged to trans,trans-1,6diphenylhexa-1,5-diene, the product of the thermal Cope rearrangement. A 100:1 ratio of alumina to diene gave approximately $50 \%$ conversion after two hours at room temperature. For the meso-diene, the same adsorbent to olefin ratio was tried, giving about $15 \%$ conversion after 70 hours at room temperature. The rearrangement product consisted of cis,transand trans,trans-1,6-diphenylhexa-1,5-diene in the ratio of about 9:1 based on VPC analysis. The analysis was complicated by the thermal rearrangement of residual meso-diene on the VPC column during analysis. 
Again the product composition paralleled that of the thermal rearrangement. Relatively few examples of catalyzed Cope rearrangements are reported in the literature. Most involve the use of a transition metal complex as the catalyst. One of the examples is the isomerization of cis,trans-1, 5-cyclodecadiene (XII) to cis-divinyl cyclohexane (XIII) in six to seven days at room temperature by means of bis-benzonitrile palladium (II) chloride or sodium choroplatinite in benzene (13).

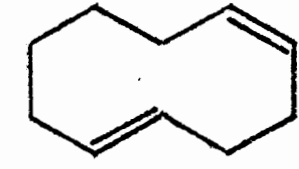

XII

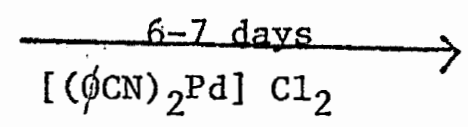

$\left[(\phi \mathrm{CN})_{2} \mathrm{Pd}\right] \mathrm{Cl}_{2}$

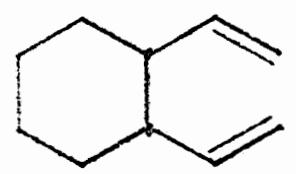

XIII

Another example may have been observed by Heimback and Brenner (14) during their attempted preparation of cis-1,2-divinylcyclobutane (XV) by dimerization of liquid butadiene (XIV) with a 1 :I mixture of bis-(cis,cis-cyclocta-1,5-diene)nickel and tris-(2-bipheny1)phosphite at roos temperature. The product contained cis,cis-cyclocta-1,5-diene (XVI) wicic is the same compound as generated from the thermal rearrangement of $\underline{c i s}-1$, 2-divinylcyclobutane at $80^{\circ}$ (14).
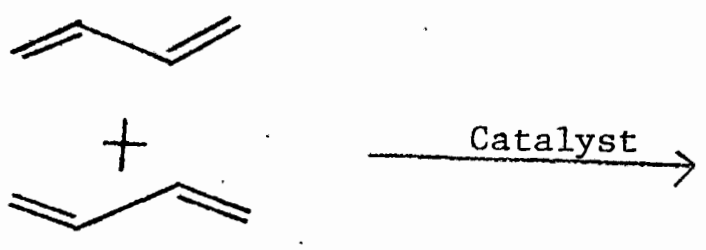

XIV

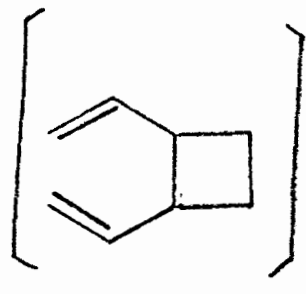

XV

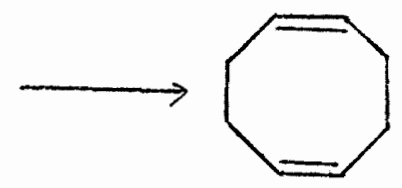

XVI 
The purpose of the research descibed here was to verify Berg's preliminary observations and to define the alumina-catalyzed Cope rearrangement more precisely in terms of reaction conditions and products. 


\section{DISCUSSION}

\section{PREPARATION OF STARTING MATERIALS}

meso- and $\mathrm{d} 1-3,4-D i p h e n y$ ihexa-1,5-diene were prepared by the general synthetic route employed by Lutz et al., (12), as outlined for the meso isomer below (Fig. 2). The method of preparation of the starting dimethyl meso- and $\mathrm{d} 1-\beta, \gamma$ diphenyladipates by reductive coupling of methyl
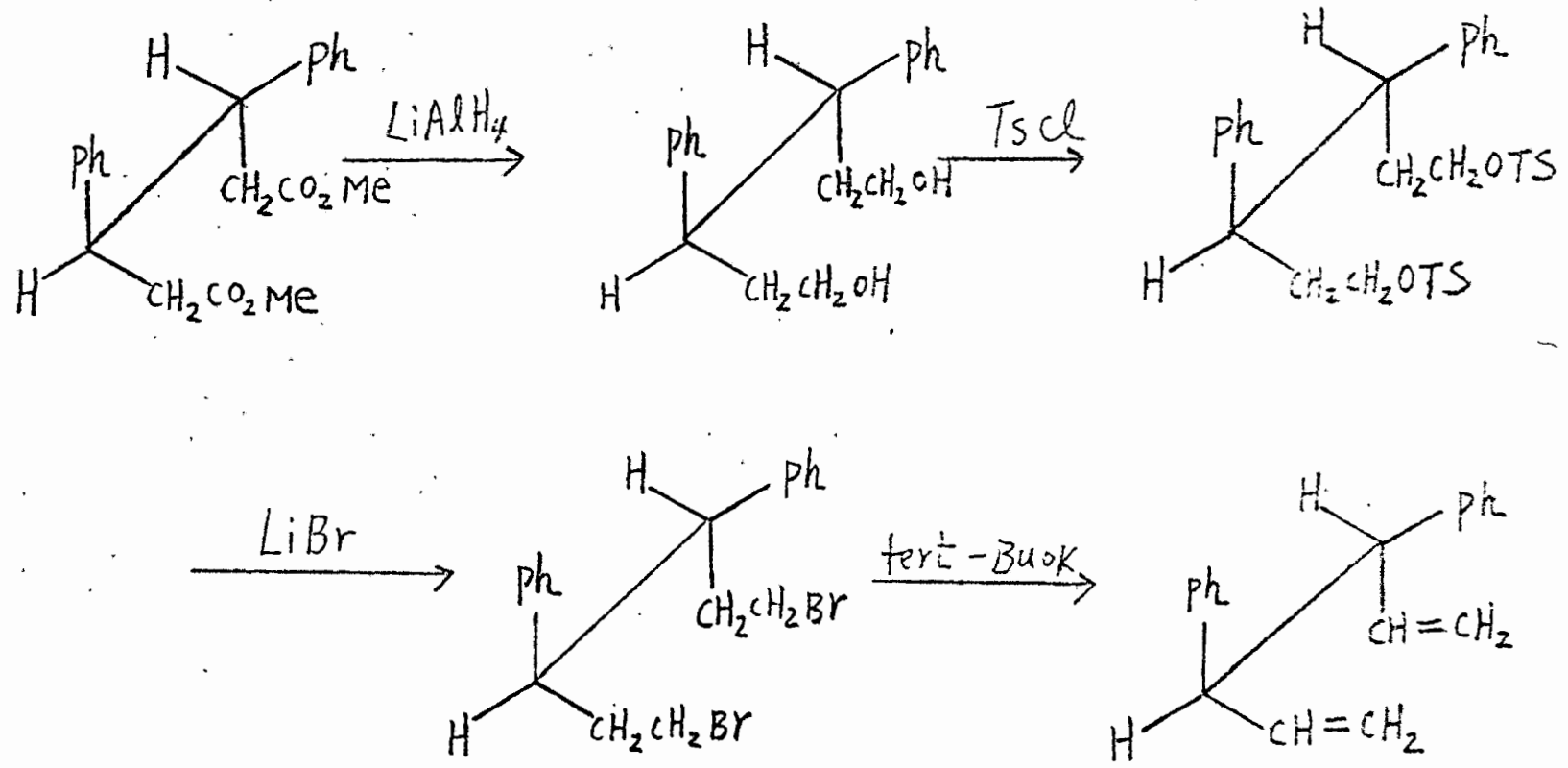

Figure 2. Synthetic route for preparing meso- and d1-3,4-dipheny1hexa-1,5-diene as illustrated for the meso isomer.

trans-cinnamate over amalgamated aluminum granules in moist ether was a considerable improvement over the previous procedure, which used aluminum 
foil. The large volume of aluminum foil was cumbersome, and its ama1gamation and subsequent use was almost uncontrollably exothermic. Elimination of the meso-bromide with a large excess of potassium tert-butoxide in a 1:1 (vo1) dimethylsulfoxide-tert-butyl alcohol solvent gave incomplete conversion to the diene. The melting point range of the meso-diene after dry column chromatography was $51-107^{\circ}$ which implied the presence of unreacted bromide. Bromide was subsequentIy isolated upon recrystallization. Evidently a longer reaction time or higher temperature is required for complete reaction on the scale used, wich was larger than that of previous preparations. Another problen was encountered during the recrystallization of cruce dl-diene from ethanol. ! Partial rearrangement of d1-diene to trans,trans-1,6-diphenylhexa-1,5diene apparently took place in boiling solvent. The contaminant could not be removed by several subsequent recrystailizations from etinanol, using. only mild heating of the solvent. Pure dl-diene was evercually obtained by TLC separation of the contaminant followed by recrystallization from ethanol under mild conditions.

\section{ALUMINA-CATALYZED REARRANGEMENT OF dI-DIENE}

A preliminary experiment was carried out at room temperature using $20 \mathrm{mg}$ of dl-diene in $2 \mathrm{ml}$ of heptane with $2 \mathrm{~g}$ of alumina (Woelm 200 , neutral, grade super I) in a $5 \mathrm{ml}$ flask capped with a glass stopper to exclude moisture. The progress of reaction was followed by periodically withdrawing samples of the reaction mixture and examining them by TLC on silver-nitrate-impregnated silica gel (see Experimenta1).

After 70 hours, the reaction appeared to be complete and the product was isolated. It showed a melting point of $73.5-76^{\circ}$ which was quite close 
to that $\left(78.9-79.2^{\circ}\right)$ of the thermal rearrangement product, trans, trans $-1,6-$ diphenylhexa-1,5-diene. VPC analysis (see Experimental) indicated that it consisted of trans,trans-1,6-diphenylhexa-1,5-diene with only traces of other components.

Another experiment was performed using $40 \mathrm{mg}$ of dl-diene in $2 \mathrm{ml}$ of heptane, and $2 \mathrm{~g}$ of alumina at $60^{\circ}$. After 1.5 hours, the crude product had a melting point of $76.0-77.5^{\circ}$. VPC analysis did not show any significant side products in addition to trans,trans-1,6-diphenylhexa-1,5-diene.

The catalyzed rearrangement was repeated using a more active alumina which was subsequently found necessary for rearrangement of the meso-diene at a convenient rate. The alumina was activated by heating for four hours at $650-700^{\circ}$, a temperature which is reported to yield maximum catalytic activity (15). Also, long-stemmed ampules closed with serum caps were used as reaction-vessels and transfer of activated alumina was carried out in a dry box.

Using $20 \mathrm{mg}$ of dl-diene in $1.0 \mathrm{ml}$ of heptane and $1 \mathrm{~g}$ of the activated alumina, rearrangement was found to be complete within 15 minutes. This was established by IR spectroscopy (Fig. 3,4). The spectrum of the crude product (mp 74.0-77.2 ${ }^{\circ}$ ) matches that of pure trans, trans-1,6-diphenylhexa-1, 5-diene (mp 78.8-79.2 ${ }^{\circ}$ ) obtained by the Grignard coupling of trans-cinnamy 1 chloride (11). VPC analysis (Fig. 5) showed the catalyzed rearrangement product had the same retention time as authentic trans, trans-diene with only trace amounts (less than $0.1 \%$ ) of impurities.

The conclusion can be made that the alumina-catalyzed rearrangement product of d1-3,4-diphenylhexa-1,5-diene at room temperature or $60^{\circ}$ is the same as that of its thermal rearrangement at $80^{\circ}$. 

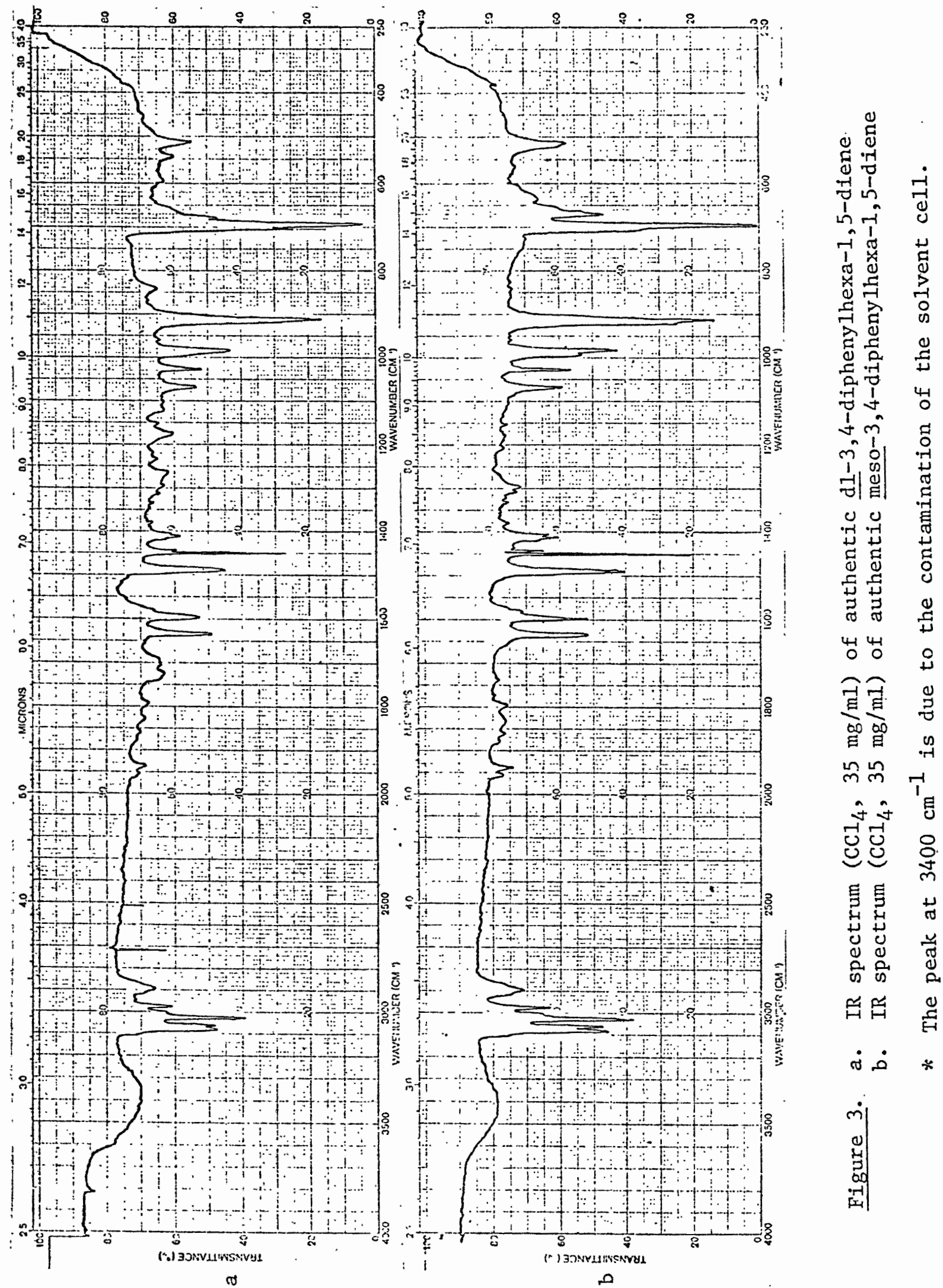


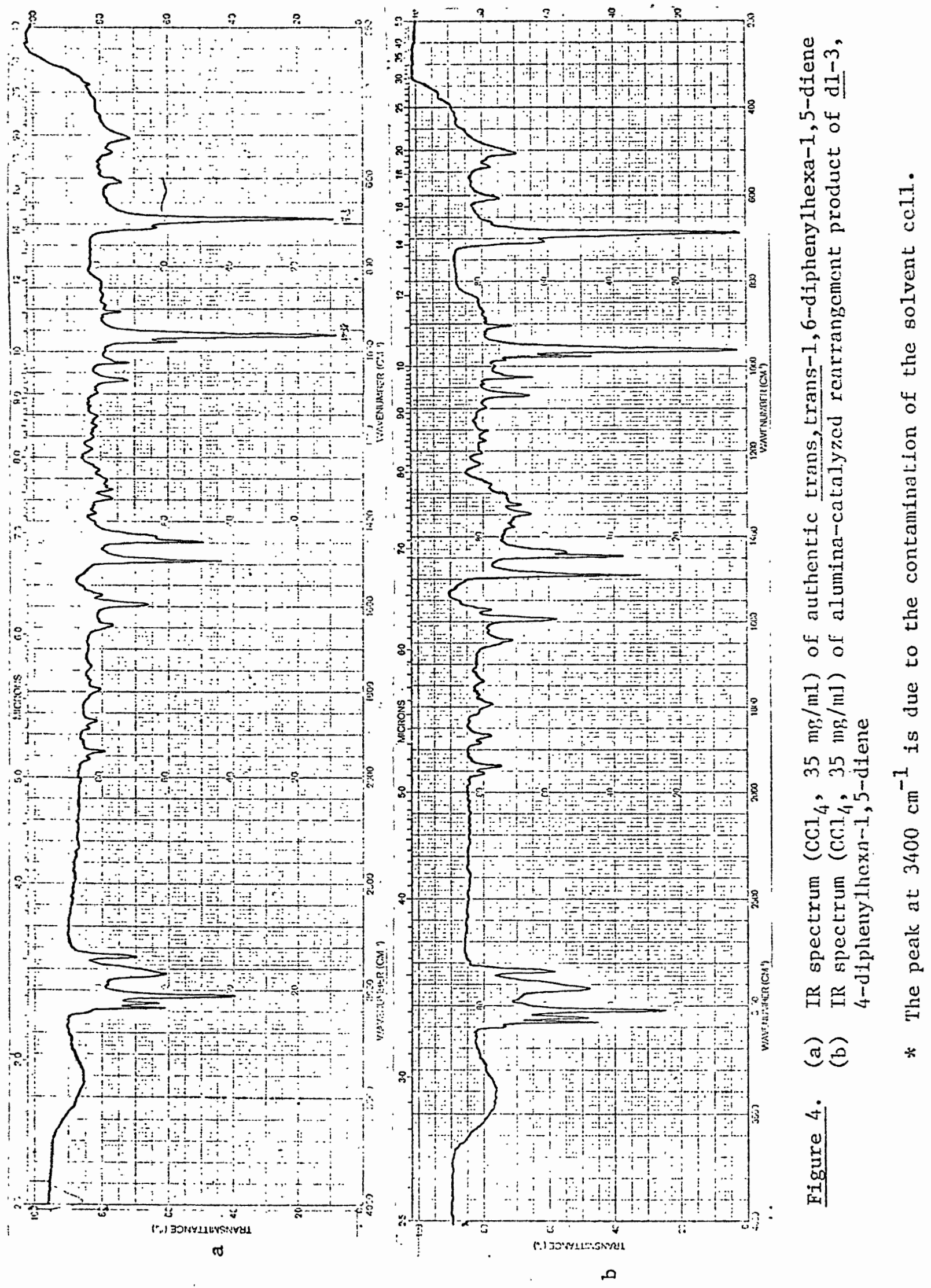




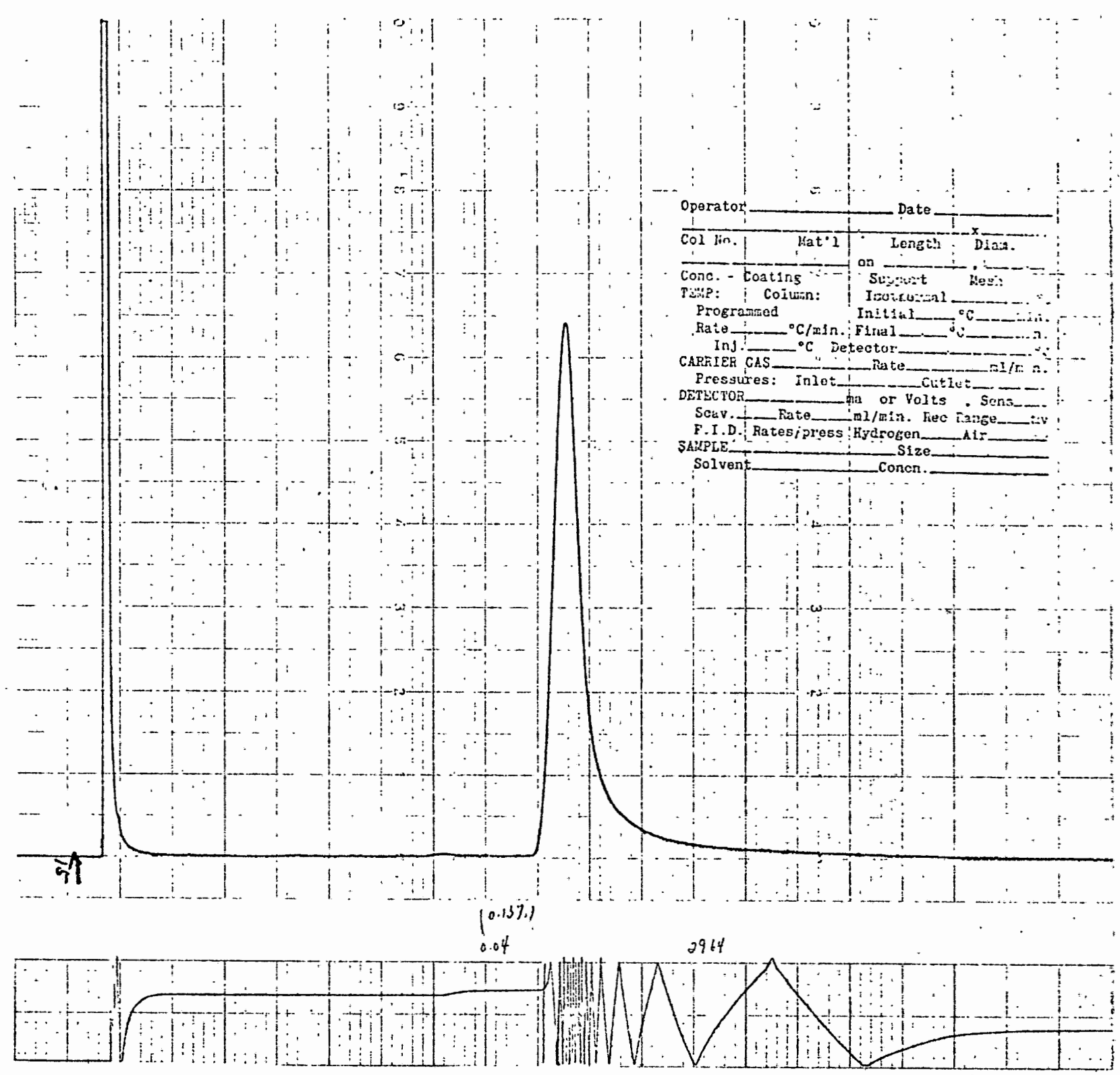

Figure 5. Vapor phase chromatogram of crude product from the alumina catalyzed rearrangement of d1-3,4-diphenylhexa-1,5-diene. 
III ALUMINA-CATALYZED REARRANGEMENT OF mESO-DIENE

The preliminary rearrangement of meso-3,4-diphenylhexa-1,5-diene was carried out at room temperature using untreated alumina (Woelm 200, neutral, grade Super I) in a 5-m1 flask capped with a glass stopper. This method proved unsuccessful, as the melting point $\left(84-85.5^{\circ}\right)$ of the sample after 20 hours was virtually identical to that of the starting meso-diene (mp 85.6-86.5 $5^{\circ}$ ).

It was found that a convenient rearrangement rate could be achieved by prior further activation of the alumina at $650-700^{\circ}$ for four hours. A11 subsequent rearrangements of the meso-diene were carried out with alumina treated this way. The method of preparing the reaction samples was also about the same as that for the dl-diene, except that the amoung of heptane solvent used was just enough to wet the alumina without the development of a supernatant liquid layer.

Analysis of the isolated crude products was more complicated than for dl-diene rearrangement, since most reactions did not go to completion. meso-Diene rearranges under the conditions of VPC analysis and had to be removed by preparative TLC on silver-nitrate-impregnated silica gel. VPC could then give an accurate ratio for the cis,trans- and trans, trans1,6-diphenylhexa-1,5-diene rearrangement products. The extent of conversion at a given reaction time was determined by quantitative IR analysis (spectra shown in Fig. 3 and 4) of the isolated crude products using the characteristic $10.4 \mu$ absorption of the product diens and an average extinction coefficient calculated using their VPC ratios. A calibration curve with pure trans, trans-diene showed linearity in the range of 
concentrations analyzed.

The first run was carried out with meso-diene:alumina in the ratio of $20 \mathrm{mg}: 2 \mathrm{~g}$ at $60^{\circ}$. After 10 hours, TLC analysis indicated the absence of meso-diene. Therefore, the crude product was subjected directly to VPC analysis. It may be seen from Fig. 6 that the rearranged product was mainly trans, trans-diene. This is contrary to the result obtained thermally and the preliminary results observed by Berg with catalysis. The appearance of cis, cis isomer was also unprecedented. Apparently an isomerization of the geometrical isomers took place on the surface of the alumina and approached an equilibrium distribution.

Because the conditions employed were too vigorous, the ratio of olefin to alumina was cut to $20 \mathrm{mg}: 1 \mathrm{~g}$ and reaction was run at room temperature for $15,30,45$, and 60 minutes. Results are summarized in Table II. VPC analysis (Fig. 7) of 60 minutes sample indicated the ratio of cis, trans-diene:trans, trans-diene was $68: 32$.

\section{TABLE II}

SUMMARY OF EXTENT OF CATALYZED REARRANGEMENT AND PRODUCT DISTRIBUTION OF mESO-DIENE AT ROOM TEMPERATURE

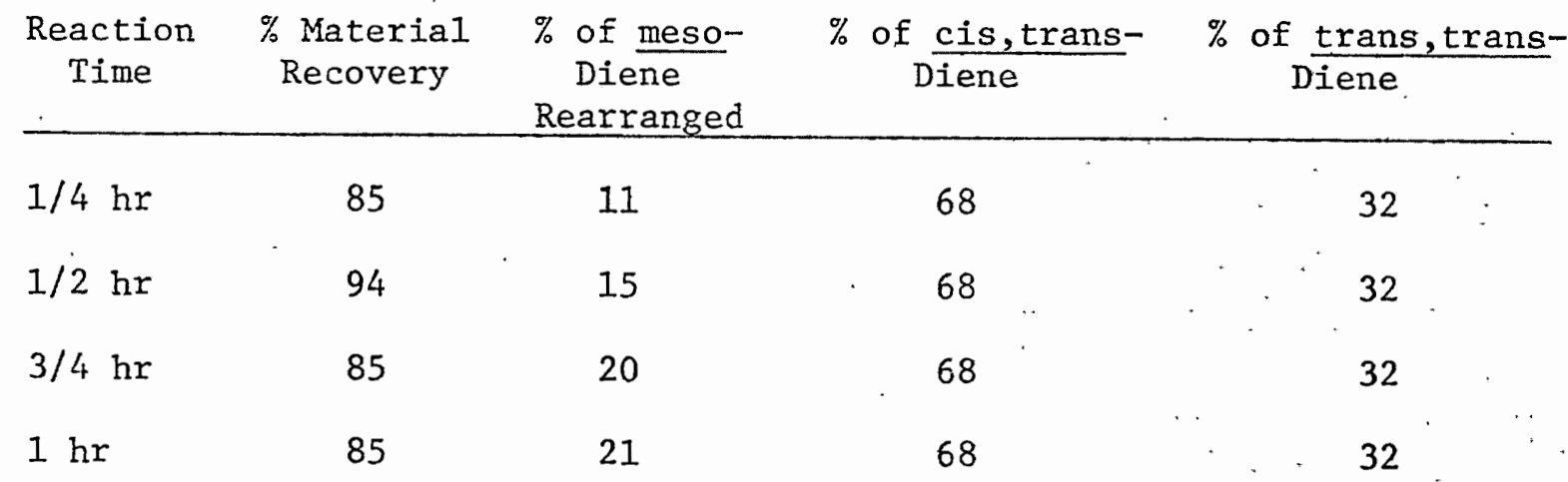




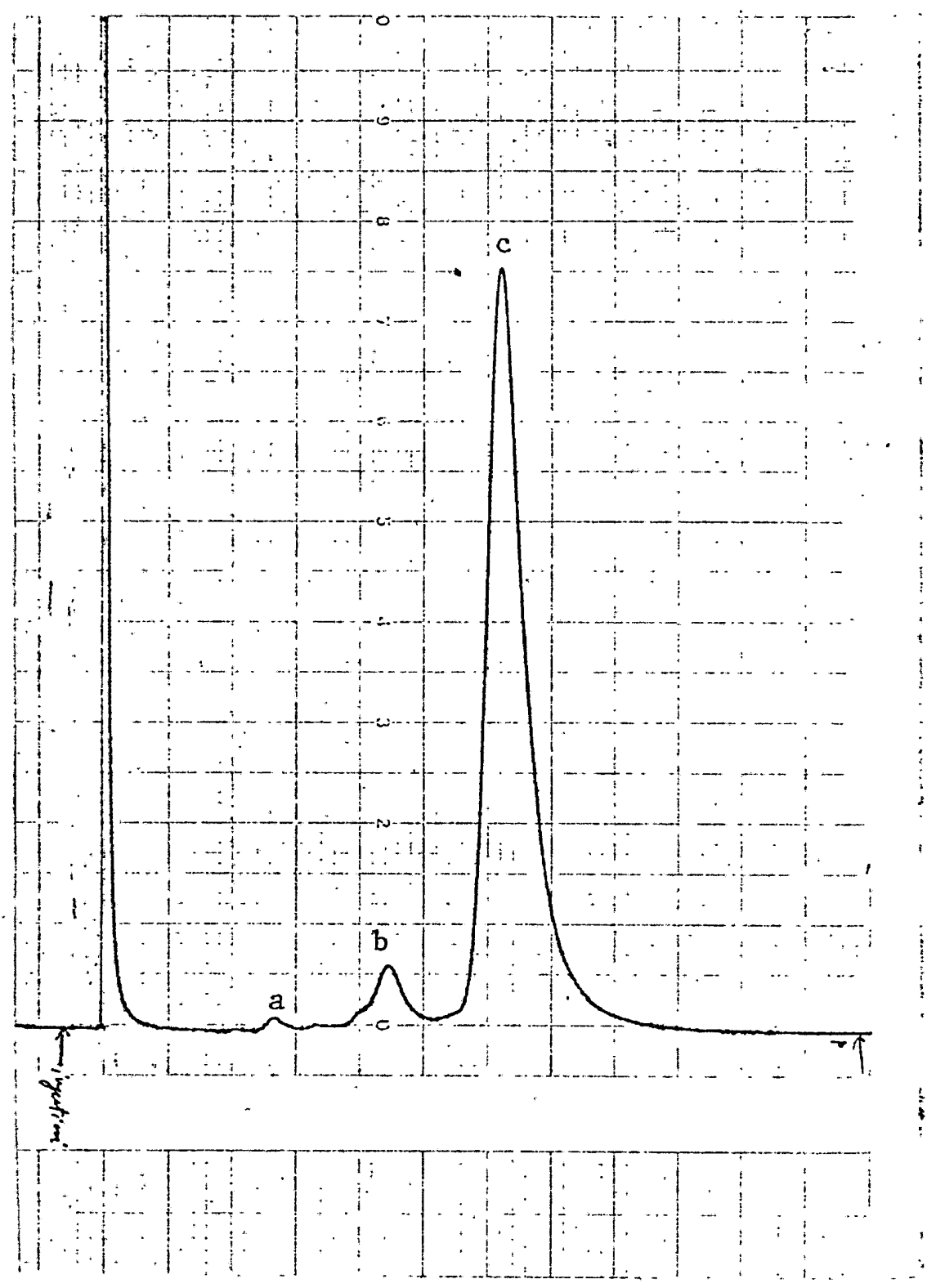

Figure 6. Gas chromatogram of meso-3,4-diphenylhexa-1,5-diene rearranged on activated alumina (diene:alumina, $20 \mathrm{mg}: 2 \mathrm{~g}$ ) at $60^{\circ}$ for 10 hours. (Column temperature $220^{\circ}$.)

a. cis,cis- b. cis,trans- c. trans,trans-1,6-diphenylhexa-1, 5-diene

Another run was performed for 1, 2, 3 and 4 hours at room temperature. Results are sumarized in Table III. 


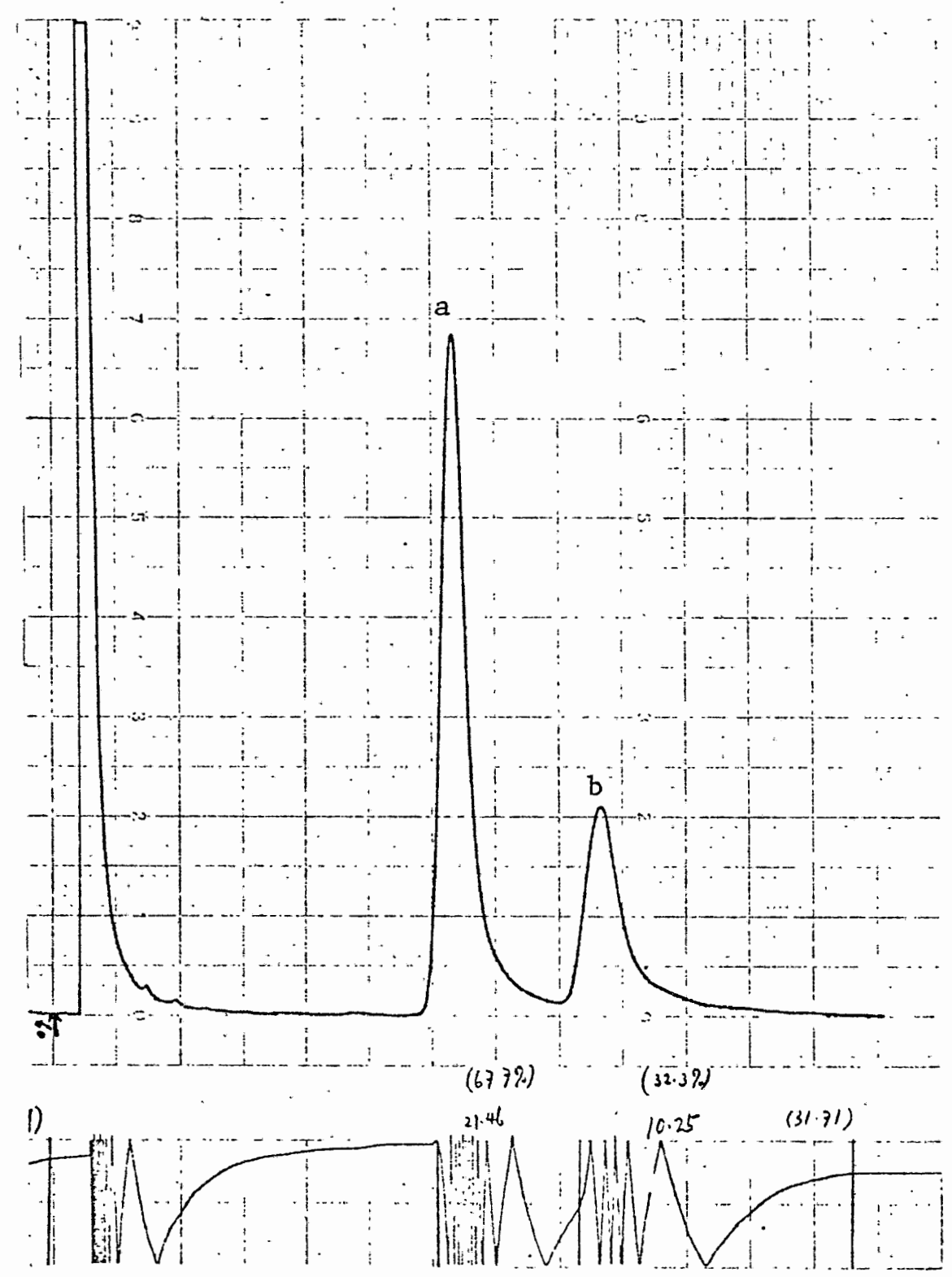

Figure 7. Gas chromatogram of meso-3,4-diphenylhexa-1,5-diene rearranged on activated alumina (diene:ajumina, $20 \mathrm{mg}: 1 \mathrm{~g}$ ) at room temperature for 60 minutes.

a. cis,trans- b. trans;trans-1,6-diphenylhexa-1,5-diene 
TABLE III

SUMMARY OF EXTENT OF CATALYZED REARRANGEMENT AND PRODUCT DISTRIBUTION OF MESO-DIENE AT ROOM TEMPERATURE

\begin{tabular}{ccccc}
$\begin{array}{c}\text { Reaction } \\
\text { Time }\end{array}$ & $\begin{array}{c}\% \text { Material } \\
\text { Recovery }\end{array}$ & $\begin{array}{c}\% \text { of meso- } \\
\text { Diene } \\
\text { Rearranged }\end{array}$ & $\%$ of $\frac{\text { cis,trans- }}{\text { Diene }}$ & of $\frac{\text { trans,trans- }}{\text { Diene }}$ \\
\hline $1 \mathrm{hr}$ & 78 & 36 & 73 & 27 \\
$2 \mathrm{hr}$ & 79 & 33 & 72 & 28 \\
$3 \mathrm{hr}$ & 90 & 40 & 68 & 32 \\
$4 \mathrm{hr}$ & 87 & 37 & 69 & 31
\end{tabular}

It appears that some rearrangement of initially formed cis,transdiene to the trans, trans-diene occurred. The initial product distribution for the catalyzed cope rearrangement was obtained by plotting the percentage of cis,trans-diene vs. reaction tiwe and extrapolations to zero time (Fig. 8). The extrapolated value of cis,trans-1,6-diphenylhexa-1, 5 -diene is $73 \%$.

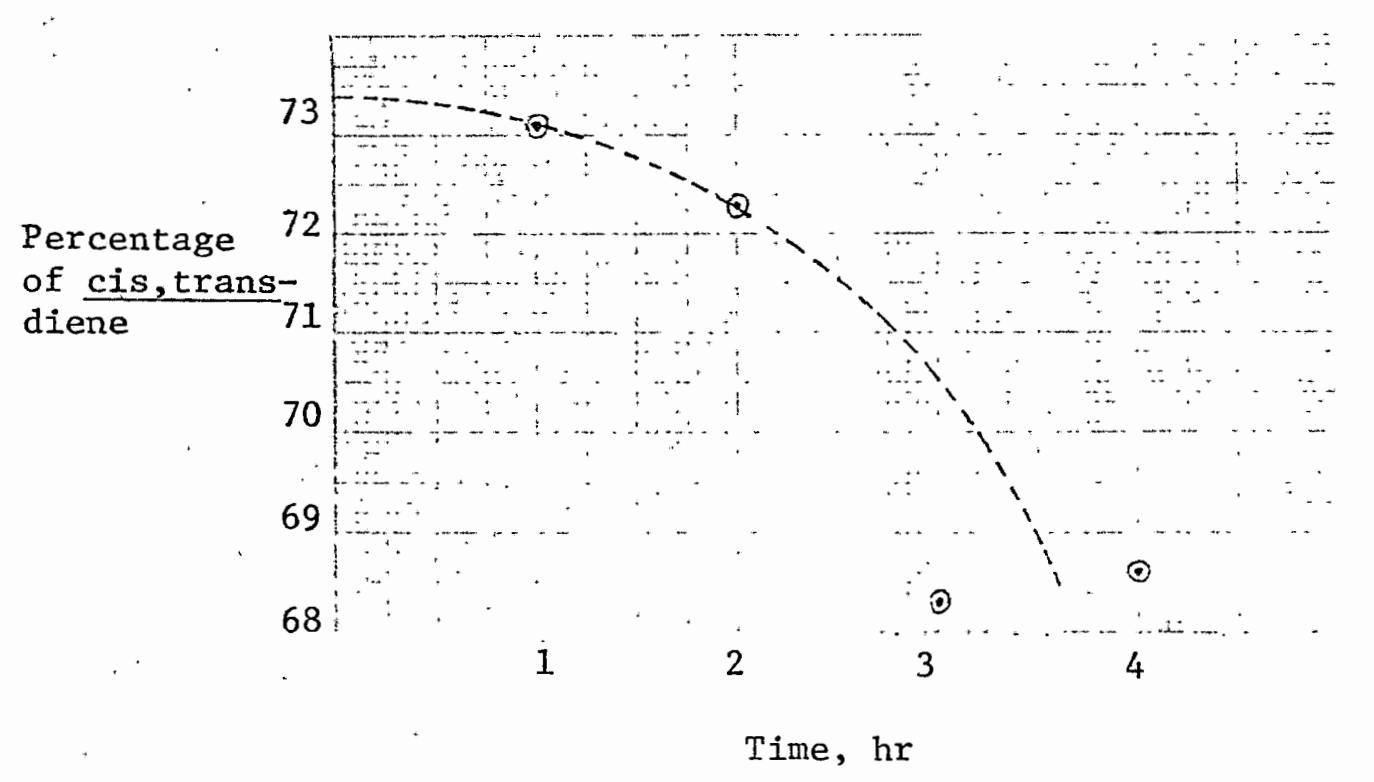

Figure 8. Product distribution for the alumina-catalyzed Cope rearrangement of meso-3,4-diphenylhexa-1,5-diene at room temperature. 
The anomalous behavior of the 3 - and 4-hour samples as well as the precent rearrangement values is characteristic of the difficulties encountered in obtaining consistent and reproducible results for the mesodiene rearrangement. Apparently minor changes in catalyst preparation and handling affect the reaction greatly. In one run at room temperature not reported here, additional peaks of significant intensity were observed on VPC analysis, with retention times larger than that of the trans,transdiene.

The final run, using the same method of sample preparation, was carried out for $15,30,45$ and 60 minutes at $60^{\circ}$. Results are summarized in Table IV. It should be noted that $110 \%$ rearrangement of meso-diene in the one hour implies an inaccurate analytical method. Visual inspection of the IR spectrum of this sample suggested actually about $95 \%$ rearrangement.

TABLE IV

SUMMARY OF EXTENT OF CATALYZED REARRANGEMENT AND PRODUCT DISTRIBUTION OF mESO-DIENE AT $60^{\circ}$

\begin{tabular}{lcccc}
$\begin{array}{c}\text { Reaction } \\
\text { Time }\end{array}$ & $\begin{array}{c}\% \text { Material } \\
\text { Recovery. }\end{array}$ & $\begin{array}{c}\% \text { of meso- } \\
\text { Diene } \\
\text { Rearranged }\end{array}$ & $\%$ of $\frac{\text { cis,trans- }}{\text { Diene }}$ & $\%$ of $\frac{\text { trans,trans- }}{\text { Diene }}$ \\
\hline $1 / 4 \mathrm{hr}$ & 95 & 53 & 46 & 54 \\
$1 / 2 \mathrm{hr}$ & 74 & 96 & 34 & 66 \\
$3 / 4 \mathrm{hr}$ & 90 & 82 & 23 & 77 \\
$1 \mathrm{hr}$ & 73 & "110" & 23 & 77
\end{tabular}

The VPC chromatogram of product isolated from the 15 minute sample is shown in Fig. 9. 


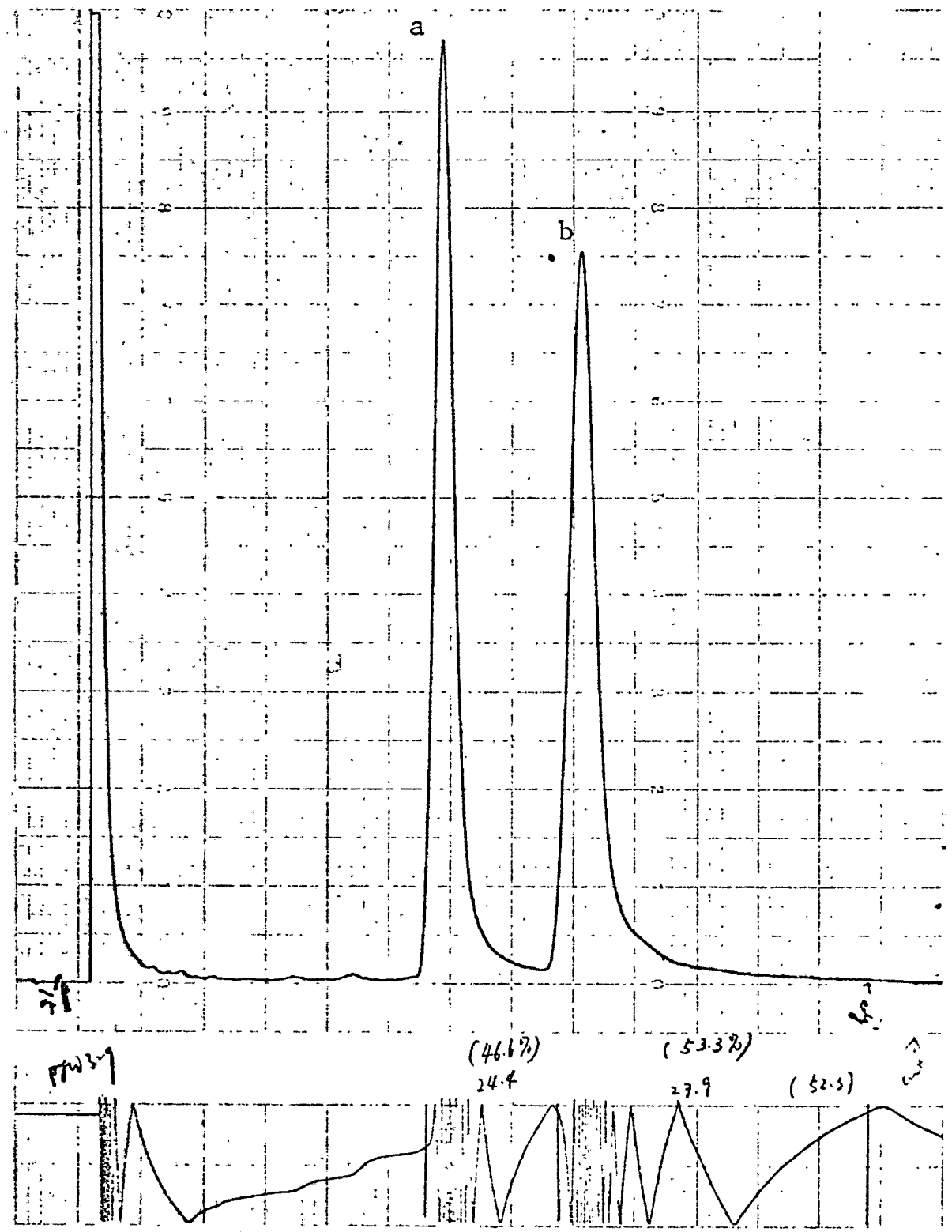

Figure 9. Gas chromatogram of meso-3,4-diphenylhexa-1,5-diene rearranged on alumina (diene:alumina $20 \mathrm{mg}: 1 \mathrm{~g}$ ) at $60^{\circ}$ for $15 \mathrm{~min}$. a. cis,trans- b. trans,trans-1,6-diphenylhexa-1,5-diene

Again it is obvious that product isomerization is taking place, and the initial percent of cis,trans-1,6-diphenylhexa-1,5-diene at $60^{\circ}$ was calculated by extrapolation from the plot shown in Fig. 10. The extrapolated value is $58 \%$. 


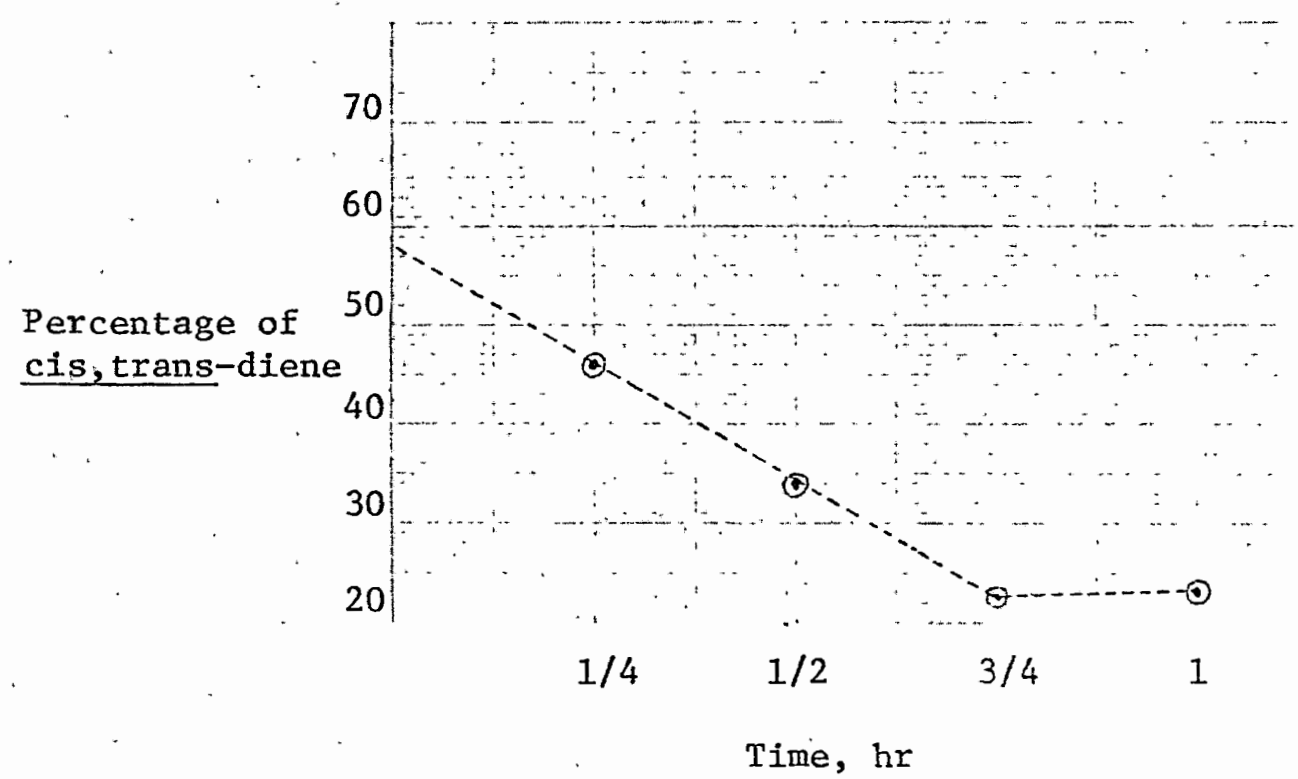

Figure 10. Product distribution for the alumina-catalyzed Cope rearrangement of meso-3,4-dipheny1hexa-1,5-diene at $60^{\circ}$

The foregoing results suggest that, as with dI-diene, the 2luminacatalyzed rearrangement of the meso-diene strikingly resembles that of its thermal Cope rearrangement. The preferences for a four-center geometry in the transition state is maintained in whatever process is responsible for reaction on the alumina surface. A control experirent was run to test the possibility. that the alumina-catalyzed rearrangement might be proceeding by fragmentation of starting diene to phenyl-substituted allyl radicals followed by recombination. Another product of recombination would be 1,4-diphenylhexa-1,5-diene which might then further isomerize to the 1,6 -diphenyl products. No 1,4-diene could be detected in the crude reaction products by visual inspection of the TLC plates. VPC analysis (four hour, room temperature sample) of the portion of the plate which would contain the 1,4-diene (see experimental part of mesodiene rearrangement Run 2) indicated nothing other than solvent was 
present. It was also found that an authentic sample of 1,4-diphenylhexa-1, 5-diene was stable to all of the reaction conditions described above and hence the catalyzed reaction could not have involved this intermediate. It has been reported by W.O. Haag and H. Pines (15) that pure alumina has intrinsic acidity. This acidity could be demonstrated by the fact that many of the reactions catalyzed by alumina are typically acid catalyzed, such as dehydration of 1-butanol and skeletal isomerization of 3,3-dimethyl butene and cyclohexene. Another example is isomerization of 1- cis-2and trans-2-butene over alumina (16). These results lead to the suggestion that the interconversion of cis,trans- and trans,trans-1,6-diphenylhexa-1, 5-diene observed in this study, takes place by a carbonium ion-type mech-anism with alumina as the Lewis acid catalyst.

As for the mechanismof the alumina-catalyzed Lope rearrangsment, there is no obvious function for a catalyst and speculations as to mechanism wil1 require further experiments as to the scope of the reaction and the activity of more simple catalysts whose behavior might be expected to parallel that of alumina such as $\mathrm{AlCl}_{3}, \mathrm{FeCl}_{3}$, etc. 


\section{GENERAI LABORATORY PROCEDURES AND INSTRUMENTATION}

Melting points were determined on a Thomas-Hoover capillary nelting point apparatus, and are uncorrected.

Infared spectra were obtained on a Perkin-Elmer 467 Grating Infared Spectrophotometer.

Vapor phase chromatography (VPC) was carried out on a Hewlett-Packard 5750B Research Chromatograph with flame ionization detectors. The column used was $1 / 8^{\prime \prime} \times 8^{\prime}$ stainless steel packed with $5 \%$ XE-60 cyanosilicone gum rubber on 80-100 mesh acid-washed silanized Chromasorb W. Al1 analysis, unless otherwise indicated, were run with the colum at $210^{\circ}$, injection port at $240^{\circ}$, detector at $230^{\circ}$. Compositions of chromatographic samples were calculated from relative peak areas as measured with a disc integrator.

A rotary evaporator operating at water aspirator vacuum was ezployed to evaporate solvents.

Alumina (Woelm 200, neutral, grade super I, approximately $200 \mathrm{~m}^{2} / \mathrm{g}$ BET surface area) was used either directly as provided by the manufacturer or was activated at $650-700^{\circ}$ for four hours in a Sybron Co. Thermolyne Type 1400 furnace. Weighings were carried out in a glove box.

A constant temperature oil bath $\left( \pm 1^{\circ}\right)$ was set up with a Thernistemp temperature controller, Model 71.

Solvents. DMSO (Dimethyl sulfoxide, Mallinckrodt analytical reagent grade) was purified by vacuum distillation at $85^{\circ}(20 \mathrm{~mm})$. The receiver, in which the distillate was stored until use, was detached from 
the "cow," sealed quickly with a glass stopper and left in a desiccator to prevent absorption of atmospheric moisture. THF (tetrahydrofuran) was allowed to react with a small amount of lithium aluminum hydride which destroyed peroxides and trace amounts of water, then subjected to simple distillation. A substantial amount of THF (up to 25\%) was left as the residue. n-Heptane (Mallinckrodt Spectra AR spectrophotometric grade) previously dried over molecular sieves was used as solvent for the alumina-catalyzed reactions.

Unless otherwise specified, solvents other than those mentioned above were of reagent quality and were used without further purification. 


\section{EXPERIMENTAL}

Methy1 Cinnamate. The procedure was adapted from that of Cinton and Laskowski (17). Cinnamic acid (444 g, 3.00 moles) was dissolved in a solution of methanol (288 $\mathrm{g}, 900$ moles) and 1,2 -dichloroethane (650 mI) in a 2000-m1 round-bottom flask. Concentrated sulfuric acid ( 45 ml) was added slowly with swirling. The reaction mixture was then refluxed for. 16 hours, with the progress of esterfication indicated by the development of an upper layer containing water, methanol and sulfuric acid. Water was added to the reaction mixture, then saturated sodium bicarbonate solution until no further evolution of carbon dioxide occurred. The acqueous layer was separated and the organic layer washed with water. Most of the ethylene dichloride was removed by distillation at atmosphere pressure, then the dark red residual liquid was vacuum distilled. A small first cut obtained at $75-92^{\circ}(1.5-0.3 \mathrm{~mm})$ was discarded. The second cut $(413 \mathrm{~g})$ accumulated at $93^{\circ}(0.3 \mathrm{~mm})$. After distillation, about 150 ml of residue was left. The yield was $84 \%$ and probably could be nigher because more cinnamate may be in the residue. The IR spectrum of the product (in $\mathrm{CCl}_{4}$ ) was virtually identical to that of an authentic sample. Dimethyl meso- and $\mathrm{d} 1-\beta, \gamma$-Diphenyladipates. The method of synthesis was essentially that employed by Oommen and Vogel (18), as modified by Wilds and Sutton (19). The modification uses aluminum granules rather than aluminum foil and it represents a distinct improvement because the reactions involved in the preparation and use of amalgamated aluminum foil are almost uncontrollably exothermic. 
First $100 \mathrm{~g}$ of 8-20 mesh "purified" aluminum granules (J. T. Baker Chemical Co.) in a $500 \mathrm{ml}$ round-bottom flask was treated with $100 \mathrm{ml}$ of $5 \%$ sodium hydroxide for three minutes, washed thoroughly with several portions of water by decantation, then amalgamated by swirling with $100 \mathrm{ml}$ of $2.6 \%$ mercuric chloride solution for three minutes, and finally washed three times with distilled water. Immediately $50 \mathrm{~g}(0.31$ mole) of methy 1 cinnamate in $200 \mathrm{ml}$ of moist ether (previously shaken with water) was added. The reaction flask was attached to a condenser and the ether refluxed from the heat of reaction with the evolution of hydrogen gas for about ten minutes. An ice bath was used to control the reaction. After thirty minutes, the rate of refluxing slowed down. Then heat was applied to maintain a constant reflux. The reaction mixture turned greenish-gray for a while and became gray eventually. A total of $25 \mathrm{ml}$ of water was added in portions from time to time during 24 hours of reflux. At the end of the reaction, the gray mixture was scraped out into a 1000-ml ice-cooled beaker containing $500 \mathrm{~m} 1$. of $18 \%$ hydrochloric acid. The mixture was stirred magnetically until the aluminum sludge was all dissolved leaving a gray suspension with aluminum granules at the bottom. During the digestion. with hydrochloric acid, ether boiled off. Then the reaction mixture was extracted with $700 \mathrm{ml}$ of benzene in three portions. The top benzene layer separated from the aqueous layer easily but showed turbidity. Then combined benzene layers were pressure filtered through a sintered glass funnel with a Celite pad to expedite filtration. The solvent was stripped off on the rotary evaporator followed by full oil-pump vacuum overnight. The crude product was a colorless semisolid $(49.3 \mathrm{~g})$, and was combined with that from another run under the same conditions to yield a total of $99.4 \mathrm{~g}$. Recrystallization from methanol gave $6.8 \mathrm{~g}$ of meso-ester (mp 169-174 ${ }^{\circ}$, 
1it. (12) $\left.172-176^{\circ}\right)$.

The mother liquor was concentrated on the rotary evaporator and the residue was subjected to vacuum distillation with an oil bath as the heat source to $100^{\circ}$, then a heating mantle. The first cut $\left[\left(63 \mathrm{~g}, 50-70^{\circ}(0.2-\right.\right.$ $0.3 \mathrm{~mm})$ ] was mainly methyl dihydrocinnamate, principal side product of the hydrodimerization reaction. The second cut $(0.8 \mathrm{~g})$ was collected at $70-160^{\circ}$ $(0.2 \mathrm{~mm})$. The third cut weighed $16.4 \mathrm{~g}\left[160-190^{\circ}(0.2 \mathrm{~mm})\right]$. The dark brown residue weighed $3.5 \mathrm{~g}$, and the total material recovery was $84 \%$ from methyl cinnamate. The viscous yellow third cut solidified in the refrigerator. Recrystallization from $125 \mathrm{ml}$ of methanol gave $0.9 \mathrm{~g}$ (mp 160-172 ${ }^{\circ}$ ) of white solid which was meso-ester. The combined crops of meso-ester represent a yield of $7.7 \%$. The second crop, $4.5 \mathrm{~g}$ (mp $68-72^{\circ}$, cloudy melt, 1 it. (12) mp $\left.71-72^{\circ}\right)$ was the dl-ester $(4.5 \%$ yield).

Under the same conditions, several coupling reactions were run using 5-mesh, 99.6\% aluminum granules (Matheson, Coleman \& Bel1). Nearly the same results were obtained.

meso-3,4-Diphenylhexane-1,6-diol. The method of synthesis was essentially that of Lutz et al., (12) except that additional quantities of lithium aluminum hydride and refluxing were needed to make the reaction go to completion. Apparently the lithium aluminum hydride had partially decomposed over several years shelf storage.

Powdered dimethyl meso- $\beta, \gamma$-diphenyladipate $(15.0 \mathrm{~g}, 0.045$ mole, $\mathrm{mp} 169-174^{\circ}$ ) was suspended in $420 \mathrm{ml}$ anhydrous ether in a $500 \mathrm{~m} 1$ corked erlenmeyer flask. Lithium aluminum hydride $(6.0 \mathrm{~g}, 0.16 \mathrm{~mole})$ was weighed out in a small capped sample vial and added slowly through a powder funnel to $150 \mathrm{ml}$ anhydrous ether in a $1000-\mathrm{m} 1$ round-bottom flask, with magnetic stirring. The residual moisture in the ether reacted with hydride to 
evolve hydrogen. Thereafter the suspension of meso-ester was introduced cautiously into the hydride solution by means of an addition funnel. A long wire was used from time to time to unplug the hole of the stopcock. After the addition, the mixture was protected with a drying tube and left for 24 hours at room temperature with magnetic stirring. An additional $2.0 \mathrm{~g}$ of lithium aluminum hydride was added and the mixture refluxed for 30 hours. Ethyl acetate $(4.0 \mathrm{~m} 1)$ was then added dropwise to the gray suspension to decompose excess hydride, followed by $300 \mathrm{ml}$ of water. White solid formed at the bottom water phase. Sulfuric acid (15\%) was added to decompose aluminum hydroxide until the aqueous phase was acid to litmus. The insoluble meso-diol was separated from the three-phase mixture by suction filtration, then washed with water and air dried to give $18.0 \mathrm{~g}$ of white solid. The crude product was recrystallized from tetrahydrofuran (with pressure filtration of the hot solution through a pad of Celite to remove insoluble matter) to yield a first crop of $8.3 \mathrm{~g}$, mp $176.5-178.5^{\circ}$ (1it. (12) $\mathrm{mp} 178.5-179^{\circ}$ ) and a second crop of $0.5 \mathrm{~g}$ ( $\mathrm{mp} 175-175.5^{\circ}$ ) for a total yield of $72 \%$.

d1-3,4-Diphenylhexane-1,6-diol. Dimethy1 d1- $\beta, \gamma$-diphenyladipate $\left(6.6 \mathrm{~g}, 0.020\right.$ mole, mp $\left.69.5-72.5^{\circ}\right)$ was suspended in $200 \mathrm{~m} 1$ dry ether (it was only partially soluble) and added in portions through an addition funnel to a magnetically stirred suspension of lithium aluminum hydride (1.6 g, 0.042 mole) in $75 \mathrm{ml}$ of dry ether. After 62 hours of stirring at room temperature, a smal1 amount of suspension was withdrawn into a 6 " test tube and water was added to decompose excess hydride. Hydrogen appeared to evolve. The mixture became separated into two phases with a white precipitate in the water layer at the bottom. The infared spectrum (in chloroform) of the dried ether layer showed a strong adsorption at 
5.78 indicating the presence of a carbonyl group. More hydride ( $1.6 \mathrm{~g}$, 0.042 mole) was then added to the reaction mixture and the mixture was stirred for another 16 hours at room temperature followed by five hours at reflux. Infrared analysis as above indicated the disappearance of the carbonyl peak. Enough water was added cautiously to the bulk ether solution with stirring until the grey color went away and a white precipitate of lithium and aluminum salts formed at the bottom. Sulfuric acid (15\%) was added until the lower aqueous phase was $\mathrm{pH} 1$. The ether layer was separated and the aqueous phase wasied with several portions of ether. The combined ether solutions were dried over anhydrous magnesium sulfate and evaporated under vacuum, leaving $5.5 \mathrm{~g}$ of a crystalIine pale yellow solid having mp 92-96. (cloudy melt, 1it. (12) mp 99$100^{\circ}$ ) Recrystallization from benzene yielded $4.8 \mathrm{~g}$ of material (87\%) with mp $99-100.5^{\circ}$ :

meso-3,4-Diphenylhexamethylene p-Toluenesulfonate. Freshly puri-

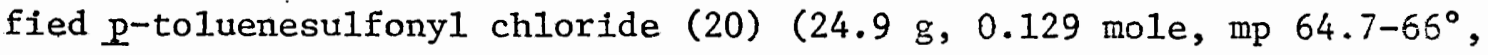
1it. (12) mp $67.5-69^{\circ}$ ) was slow.1y added with stirring to an ice-cold solution of the meso-diol $(8.8 \mathrm{~g}, 0.032 \mathrm{~mole}$ ) in $210 \mathrm{ml}$ of dry (molecular sieves) pyridine. The solution turned pale yellow after a short period and was allowed to stand in the refrigerator overnight corked tightly. Tosylation was indicated by the presence the next day of needlelike crystals of pyridinium hydrochloride. The resulting mixture was poured with stirring into about $1000 \mathrm{~g}$ of ice and the precipitated tosylate was suction filtered after the ice melted, then washed with water, and dried. During recrystallization from 2:1 (vol) ethyl acetatecarbon tetrachloride, a water layer was observed and removed by pouring anhydrous magnesium sulfate into the solution. The solution was then 
kept hot for a few minutes and filtered. The purified tosylate weighed

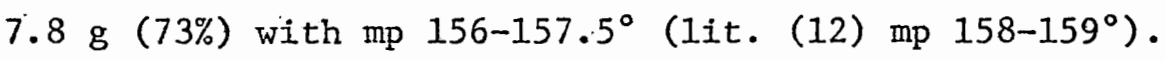
d1-3,4-Diphenylhexamethylene $\mathrm{p}$-Toluenesulfonate. d1-3,4-Dipheny1hexane-1,6-diol $(4.8 \mathrm{~g}, 0.018$ mole, mp 99-100.5 $)$ was dissolved in $100 \mathrm{ml}$ of pyridine previously dried over molecular sieves and the solution was brought to $0^{\circ}$ in an ice bath. To this was added $13.8 \mathrm{~g}$ (0.072 mole) of freshly purified p-toluenesulfonyl chloride slowly and with stirring, keeping the temperature as close to $0^{\circ}$ as possible. The resulting solution was placed in the refrigerator overnight, during which time pyridine hydrochloride precipitated. The reaction mixture was poured over ice $(200 \mathrm{~g})$, stirred, and warmed to room temperature. 'The aqueous layer was filtered and the solid gummy product taken up in dichloromethane. The dichloromethane solution was washed with water, dried over anhydrous magnesium sulfate and evaporated on the rotary evaporator followed by application of full oil-pump vacuum for several hours. A portion of the residual gum was caused to solidify by rubbing with warm cyclohexane in a 6 " test tube for 5 minutes. This was used to seed the bulk sample. The crude sample was recrystallized from methanol to yield $6.8 \mathrm{~g}(66 \%)$, mp 95.5-99 (1it. (12) $\left.\operatorname{mp} 99 \cdot 5-101.5^{\circ}\right)$ meso-1,6-Dibromo-3,4-diphenylhexane. Lithium bromide (4.7 g, 0.054 mol.e) was weighed up rapidly in a $250 \mathrm{ml}$ round-bottom flask fitted with a magnetic stirrer. meso-3,4-Diphenylhexamethylene $\mathrm{p}$-toluenesulfonate $(7.8 \mathrm{~g}$, 0.013 mole) was rapidly introduced and reagent acetone (50 m1) was poured into the mixture of halide and ester. A reflux condenser with drying tube was attached to the reaction flask, and the contents were stirred magnetically and refluxed overnight. After cooling to room temperature, solvent was carefully removed on the rotary evaporator followed by the vacuum pump. 
Water was poured into the residue and the mixture suction filtered followed by washing with several portions of water (rather important here to remove Iithium salts). The air-dried product $(4.8 \mathrm{~g}$, mp 135-145 ) was recrystallized from cyclohexane to give $4.6 \mathrm{~g}$ (85\%) dibromide with $143-145^{\circ}$ (1it. (12) mp $\left.140-142^{\circ}\right)$.

d1-1,6-Dibromo-3,4-diphenylhexane. Lithium bromide $(5.5 \mathrm{~g}, 0.046$ mole, $100 \%$ excess) was dissolved in $50 \mathrm{ml}$ of reagent acetone. $\mathrm{dl}-3,4-$ Diphenylhexamethylene p-toluenesulfonate $(6.8 \mathrm{~g}, 0.012$ mole) was added, and the resulting solution allowed to reflux overnight, stirred regnetically, protected with a drying tube. (A precipitate began to form about 15 minutes after reflux was started.) Solvent was carefully removed on the rotary evaporator, and the residue dried at full oil-pump vacuum for several hours. Water was then added, leaving an insoluble sticky material which was scraped out and filtered. Several portions of water were used to wash out the lithium salts. The crude product $\left(4.8 \mathrm{~g}\right.$, mp $58-63^{\circ}$, cloudy melt) was recrystallized from methanol to give $3.4 \mathrm{~g}$ (74\%) with up 59.5$62.5^{\circ}$ (1it. (12) mp 62-63. $5^{\circ}$ ).

Attempted Preparation of meso-3,4-Dipheny1-hexa-1,5-diene. The reaction described below gave largely recovered starting material, although the procedure was successful in previous preparations on a smaller scale (12). A solution of potassium tert-butoxide was prepared by dissolving, with the aid of magnetic stirring, $9.2 \mathrm{~g}(0.097$ mole) of the base in $83 \mathrm{ml}$ of 1:1 (vol) tert-butyl alcohol and freshly vacuum distilled dimethyl sulfoxide. Some flocculent material remained undissolved. The meso-dibromide ( $4.6 \mathrm{~g}, 0.011$ mole) was then added to give a yellow mixture containing additional undissolved material. The mixture was protected with a drying tube and stirred for 30 minutes at room temperature. The mixture was 
poured over $460 \mathrm{~g}$ of ice to precipitate a yellow gummy solid. Excess base was immediately neutralized with $18 \%$ hydrochloric acid to the phenolphthalein end point. When the ice had melted, the mixture was extracted with $600 \mathrm{ml}$ of dichloromethane-in three portions. The extracts were combined, washed twice with water, dried over anhydrous magnesium sulfate and evaporated to dryness to yield $4.0 \mathrm{~g}$ of crude product (yellow oil). Infared examination of the crude product did not show any unreacted bromide. The sample was purified by dry-column chromatography. The column was made by pouring $525 \mathrm{~g}$ of silica gel (Woelm dry-column grade, $0.5 \%$ inorganic fluorescent indicator) into a nylon tube (100 x $5 \mathrm{~cm}$ flat width) with a glass wool plug at the bottom. The bottom of the tube was pierced with a syringe to create vent holes. The silica gel was covered with a layer of sand. The crude product was dissolved in a few $\mathrm{ml}$ of technical grade hexane and the solution spread uniformly on the sand with a dropper. This was followed by elution with hexane from a separatory funnel. During the development, the progress of separation was examined under short-wave length ultraviolet light. The suspected meso-diene region showed a dark bank compared to a green fluorescence of the other part. After development, the columin was cut into sections and meso-diene was leached from the second quarter-section with five $60 \mathrm{ml}$ portions of hexane followed by $500 \mathrm{ml}$ dichloromethane. The hexane elution gave $1.9 \mathrm{~g}$ of pale yellow

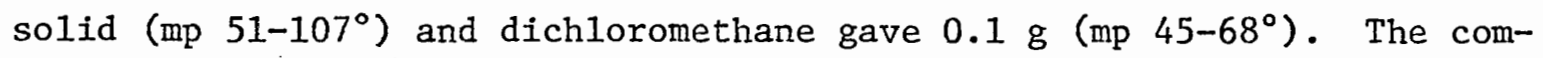
bined crops $(2.0 \mathrm{~g})$ were recrystallized from ethanol to yield a first crop $\left(0.212 \mathrm{~g}, \mathrm{mp} 124-137^{\circ}\right)$ which was identified by infared analysis as unreacted bromide; second crop $(0.327 \mathrm{~g}$, mp 74-114 $)$; third crop $(0.23 \mathrm{~g}$, $\left.\mathrm{mp} 74-85^{\circ}\right)$ and the residue $\left(0.380 \mathrm{~g}, \mathrm{mp} 62-67.5^{\circ}\right)$. No further attempts were made to isolate pure meso-diene from these crops. There is no obvious 
explanation for the failure of the reaction in this case.

d1-3,4-Dipheny1hexa-1,5-diene. Potassium tert-butoxide (18.8 g,

0.193 mole) was dissolved with magnetic stirring in $169 \mathrm{ml}$ of a $1: 1$ (vol) mixture of tert-butyl alcohol and dry (molecular sieves) dimethyl sulfoxide. Some flocculent material remained undissolved. d1-1,6-Dibromo3,4-diphenylhexane $(9.4 \mathrm{~g}, 0.024 \mathrm{~mole})$ was added to give a yellow mixture which was magnetically stirred at room temperature protected from atmospheric moisture. The mixture was stirred for 35 minutes then poured into about $600 \mathrm{~g}$ of ice in a beaker. Excess base was neutralized with 18\% hydrochloric acid to phenolphthalein end point immediately. When the ice had melted, the mixture was extracted with four $120 \mathrm{ml}$ portions of dichloromethane. The extracts were combined, washed twice with water, dried over magnesium sulfate, and evaporated under vacuum to yield $6.2 \mathrm{~g}$ of pale yellow oil.

The diene was purified by dry-column chromatography on $987 \mathrm{~g}$ of silica gel (Woelm dry-column grade, $0.5 \%$ inorganic fluorescent indicator) in a nylon tube (100 x $8 \mathrm{~cm}$ flat width). The column was developed with hexane, and the progress of separation was indicated by ultraviolet light as described for the meso-diene. The portion of the column containing the suspected d1-diene was washed with hexane and dichloromethane. The combined washings were evaporated under vacuum to yield $2.3 \mathrm{~g}$ of pale yellow solid with mp $30-34.5^{\circ}$. This sample was combined with $0.5 \mathrm{~g}\left(\mathrm{mp} 29-34^{\circ}\right)$ of the equivalent material from another run at the same conditions and the total was recrystallized from freshly distilled ethanol. It was found that the melting point of the diene after several recrystallizations was not improved. Infared analysis revealed that the compound had undergone partial rearrangement to trans,trans-1,6-diphenylhexa-1,5-diene, probably 
during an early recrystallization with boiling solvent. Subsequent recrystallizations were carried out with mild heating of the solvent followed by chilling in ice and suction filtration in a cold room. The contaminant could be separated by. TLC on silver-nitrate-impregnated silica ge1. (The details appear in the following section.) For each $20 \times 20 \mathrm{~cm}$ plate, $200 \mathrm{mg}$ of impure diene could be purified. The lower part containing dl-diene was scraped off and eluted with ethyl ether to give a total of $789 \mathrm{mg}$ ( $85 \%$ recovery) out of $955 \mathrm{mg}$ starting material. The crude diene (mp 33.5-35') was recrystallized from ethanol to give $294 \mathrm{mg}$ having $\mathrm{mp} 34.7-35.6^{\circ}$, and a second crop weighing $139 \mathrm{mg}$ (mp 33.5-35.2 ${ }^{\circ}$, 1it. (12) $\left.\operatorname{mp} 35.0-35.2^{\circ}\right)$.

Thin Layer Chromatography of 1,6-Dipheny1hexa-1,5-dienes in the Presence of 3,4-Diphenylhexa-1,5-dienes. A slurry. was prepared by mixing enough TLC silica gel (Merk, $\mathrm{HF}_{254}$ ) with $10 \%(w)$ aqueous silver nitrate solution to give a satisfactory consistency for coating (about $40 \mathrm{~g}$ silica gel per $100 \mathrm{ml}$ of silver nitrate solution). The silica gel plates made by this procedure contained about $20 \%(w)$ of silver nitrate. Microscope slides $(25 \times 75 \mathrm{~mm})$ were dipped into the slurry and then air dried. Before use, they were activated by heating at $110^{\circ}$ for one hour. After solvent development, the plates were dried and then sprayed with $0.1 \% 2,7$-dichlorofluorescein in a 50:50(vol) solution of ethanol:water. The plates were examined under long wave length ultraviolet light to show a bright spot where a sample component occurred. Also, a dark spot appeared under short wave length ultraviolet light without spraying with the 2,7-dichlorofluorescein solution.

Tests with a series of different mixtures of solvent showed that a 70:30(vo1) ratio of carbon tetrachloride:acetone was the most effective 
in separating the meso-3,4-dipheny1-hexa-1,5-diene from a mixture of the three isomeric 1,6-diphenylhexa-1,5-dienes. The latter migrated together and appeared as one spot. For the dl-diene the solvent was a 50:50 (vol) mixture of carbon tetrachloride:acetone.

The analysis was repeated using $5 \times 20 \mathrm{~cm}$ plates to enhance the separation. With the edges in alignment, five to six plates were placed side by side and two edges taped to a supporting glass plate. The slurry was then poured on the plates and drawn evenly by rolling a glass rod over. them. Then thickness of the film was dependent upon the layers of tape used.

The identification of spots was made by comparison with known samples on the same plate. The separations are shown in Figure 11 .

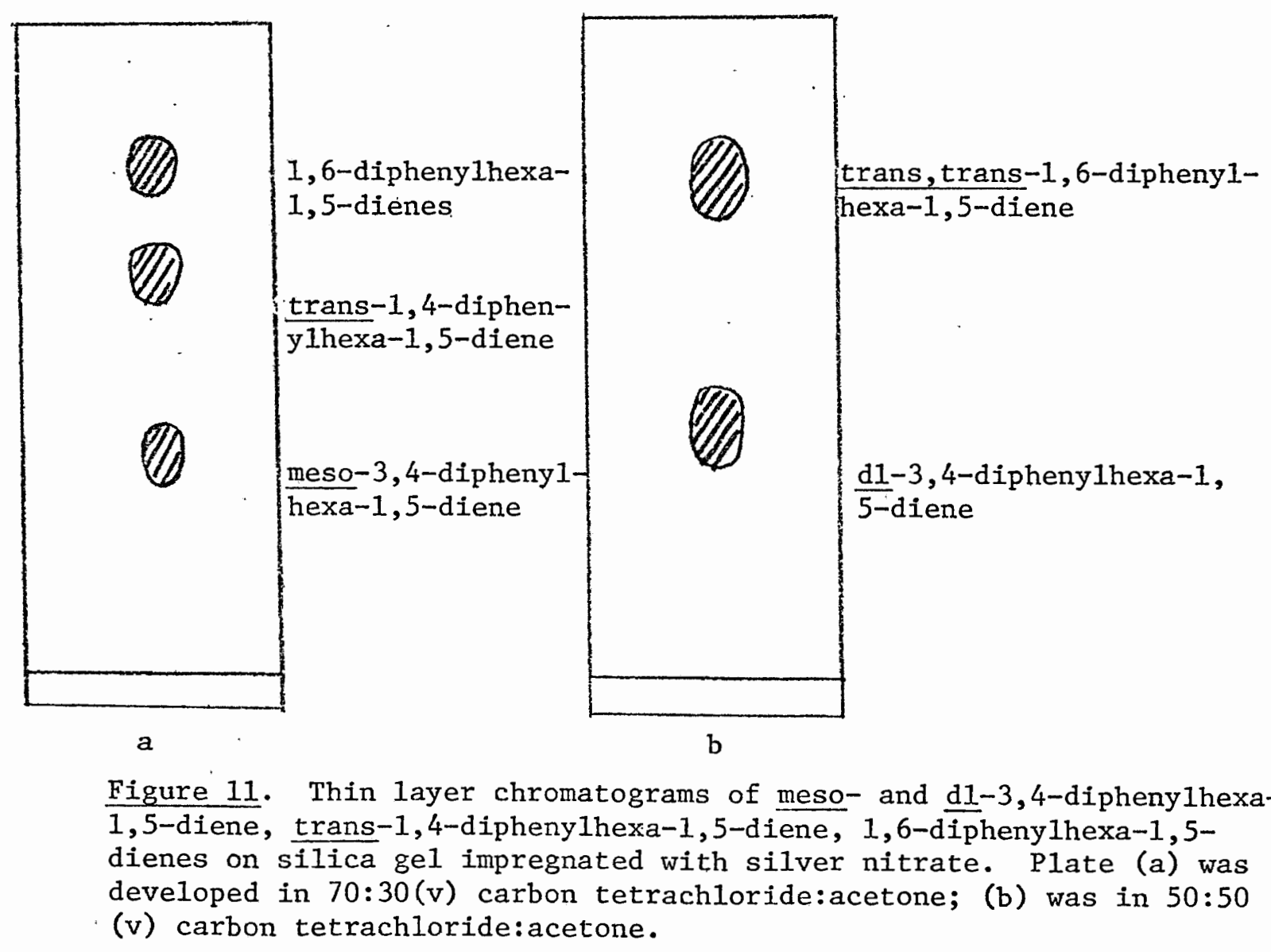


The behavior of trans-1,4-diphenylhexa-1,5-diene was also examined by TLC in the presence of meso- and 1,6-diphenylhexa-1,5-dienes.

Rearrangement of d1-3,4-Diphenylhexa-1,5-diene on Aluminum Oxide.

Run 1. A 90-mg sample of d1-3,4-diphenylhexa-1,5-diene (mp 34.7-35.6 ) was dissolved in $4.5 \mathrm{ml}$ of Spectra grade heptane previously dried over molecular sieves. Aluminum oxide (Woelm 200, neutral, activity grade super I) was activated at $650-700^{\circ}$ for four hours and cooled in a desiccator with phosphorous pentoxide as drying agent. Then the desiccator was moved to a dry box which was purged overnight. For each of four clean, preweighed Pyrex ampules ( $5 \mathrm{ml}$ ), approximately $1 \mathrm{~g}$ of aluminum oxide was poured in by estimation. Then the four ampules were closed with rubber serum caps and weighed again. The weight of aluminum oxide could be obtained by subtraction. Using a $0.25 \mathrm{ml}$ syringe, the prescribed amount of diene solution was injected into each ampule to obtain a diene:alumina ratio of $20 \mathrm{mg}: 1 \mathrm{~g}$. Then the four samples were allowed to stand for 15 , 30, 45 and 60 minutes at room temperature with frequent manual shaking. After 15 minutes, the neck of the first ampule was cut off and dichloromethane was introduced. Along with the solvent, the yellow colored alumina was pulled out by a long neck dropper and transferred to a sintered glass funne1. The mixture was pressure filtered. A small amount of methanol was added to wash off any strongly bound compounds. The solvent was stripped off on the rotary evaporator followed by the vacuum pump. The remaining three samples were dealt with in the same way. Infared analysis of the crude products showed that even within 15 minutes the reaction had gone to completion. The IR spectra of all crude samples were virtually identical to that of an authentic sample of trans, trans-1,6-diphenylhexa1,5-diene (refer to Figure 4). VPC confirmed that this was the major 
product, with only trace amounts of other impurities (Fig. 5). Melting point data for the crude products and the percentage material recovery are listed below.

\begin{tabular}{ccc}
\hline TIME & MELTING POINT & RECOVERY \\
\hline $1 / 4 \mathrm{hr}$ & $74.0-77.2^{\circ}$ & $84 \%$ \\
\hline $1 / 2 \mathrm{hr}$ & $73.5-76.6^{\circ}$ & $94 \%$ \\
\hline $3 / 4 \mathrm{hr}$ & $75.5-77.5^{\circ}$ & $87 \%$ \\
\hline $1 \mathrm{hr}$ & $73.5-76.0^{\circ}$ & $84 \%$ \\
\hline
\end{tabular}

Run 2. d1-Diene (20 mg) was dissolved in $2 \mathrm{ml}$ of heptane (AR grade) and added to $2 \mathrm{~g}$ of alumina (directly from the can) in a $5 \mathrm{ml}$ flask at room temperature. The reaction flask was sealed with a glass stopper to exclude moisture. After 70 hours, the crude product, isolated as in the previous run, had mp 73.5-76.0 . VPC analysis showed that it consisted of trans,trans-1,6-diphenylhexa-1,5-diene with only traces of other components.

Run 3. The reaction was repeated using $40 \mathrm{mg}$ of $\mathrm{dl}$-diene in $2 \mathrm{ml}$ of heptane, and $2 \mathrm{~g}$ of alumina (directly from the can) at $60^{\circ}$. After 1.5 hours, the product was isolated as before and found to have mp 76.0$77.5^{\circ}$ VPC analysis did not show any significant products other than trans, trans-1,6-dipheny1hexa-1,5-diene.

Rearrangement of meso-3,4-Diphenylhexa-1,5-diene on Aluminum 0xide. Run 1. meso-3,4-Diphenylhexa-1,5-diene ${ }^{*}$ (100 mg, mp 85.6-86.5 , 1it. (12) $\mathrm{mp} 86-87^{\circ}$ ) was dissolved in $4 \mathrm{ml}$ of heptane (spectra grade, previously prepared by $\mathrm{H}$. Berg. 
dried over molecular sieves) to give a solution of $25 \mathrm{mg} / \mathrm{ml}$. Approximately $1 \mathrm{~g}$ of Woelm grade super I neutral alumina, which was activated at $650-700^{\circ}$ for 4 hours, was poured into each of four clean preweighed Pyrex ampules in a dry box. By means of a $0.25 \mathrm{ml}$ syringe, precise amounts of meso-diene solution were injected into the ampules to give a meso-diene: alumina ratio equivalent to $20 \mathrm{mg}: 1 \mathrm{~g}$. Then the ampules were allowed to stand at room temperature with occasional manual shaking. During the course of reaction, the mixtures acquired a pale yellow color. After 15, 30, 45 and 60 minutes, the neck of an ampule was cut and dichloromethane was injected. The solution, together with the alumina, was transferred by a long stem dropper into a sintered glass funnel and eluted with dichloromethane, then methanol. Each of the four samples was evaporated to dryness and the residues dried with full oil-pump vacuum.

Infared examinations of the semisolid crude products showed only a small amount of rearranged material (refer to Table II) in addition to unrearranged meso-diene. The rearrangement products presumably were a mixture of cis,trans- and trans,trans-1,6-diphenylhexa-1,5-dienes; absorption characteristic of the trans disubstituted double bonds present in these compounds was observed at 10:37 $\mathrm{U}$. For the one hour sample, there was about $20 \%$ rearrangement of the meso-diene. The extent of reaction was calculated from an average extinction coefficient for cis,transdiene $\left(0.67 \mathrm{ml} \mathrm{mg}^{-1} \mathrm{~cm}^{-1}\right)$ and trans,trans-diene $\left(1.97 \mathrm{ml} \mathrm{mg}^{-1} \mathrm{~cm}^{-1}\right)$, where the ratio of the two compounds was obtained from subsequent VPC analysis. A calibration curve of absorbance versus concentration for trans,trans1,6-diphenylhexa-1,5-diene was run and it showed linearity up to the con-. centration of $35 \mathrm{mg} / \mathrm{ml}$.

The separation of meso-diene from its rearrangement products was 
carried out on silver-nitrate impregnated (about 20\%) silica gel ( $\mathrm{HF}_{254}$ ) TLC plates $(5 \times 20 \mathrm{~cm})$. After development in 70:30 (v) carbon tetrachloride:acetone, there appeared a dark spot on the upper part of the plate when examined under short wave length ultraviolet light. This region, which contained 1,6-diphenylhexa-1,5-dienes, was scraped off and eluted with dichloromethane.

VPC analysis (Fig. 7) of the eluates showed two resolved peaks having retention times corresponding to those of cis,trans- and trans, trans-dienes with an approximately average ratio of 68:32. (Details are given in Table II.)

Run 2. Four samples were prepared according to the method of Run 1 and they were allowed to react for $1,2,3$, and 4 hours at room temperature. The same IR, TLC and VPC analytical methods were applied. VPC analysis of the one hour sample showed a ratio of 73:27 cis,trans-diene:trans,transdiene.. There appeared a slight shoulder right after the trans,trans-diene on the chart. The shoulder intensity became more conspicuous with the longer period of catalyzed reaction. There also appeared to be an isomerization of cis,trans- to trans,trans-diene. The ratio varied from $73: 27$ (one hour) to $69: 31$ ( 4 hours). There was $73 \%$ of cis,trans-diene calculated by extrapolating to zero reaction time. For the 4 hour sample, approximately $31 \%$ of meso-diene had reacted. In this run, a VPC test of the 4 hour sample was made for the presence of trans $-1,4-$ diphenylhexa-1,5-diene in the crude rearrangement mixture, although no 1,4-diene was detected during TLC separation of unreacted meso-diene. (See the section on TLC analysis.) That portion of the TLC plate which would have contained the 1,4-diene was eluted with dichloromethane and the eluate examined by VPC. No components other than solvent were present. 
Details are given in Table III.

Run 3. Four samples prepared as above were run at $60^{\circ}$ for 15,30 , 45 and 60 minutes. At the end of the reaction time, the crude samples were isolated and analyzed as in the previous runs. For the one hour sample, IR analysis indicated $110 \%$ of meso-diene reacted, which implied an inprecise analytical method. By comparing this spectrum with that of an authentic sample of trans,trans-diene, the qualitative estimate was made that $5 \%$ of meso-diene remained unreacted. VPC analysis (Fig. 9) showed that the ratio of cis,trans-diene to trans,trans-diene decreased from 46:54 (15 minutes) to 23:77 (60 minutes), which clearly indicated that the cis,trans-diene was isomerizing on the alumina. The ratio extrapolated to zero reaction time was 58:42. Details are given in Table IV.

Run 4. This was an earlier run than those mentioned above. AIumina was activated at $650-700^{\circ}$ for 4 hours. The meso-diene to alumina ratio was decreased to $20 \mathrm{mg}: 2 \mathrm{~g}$ and the reactions carried out at $60^{\circ}$. The crude samples were isolated as indicated above. A small part of the 10 hour sample was examined by TLC, showing that most of the mesodiene had been converted to products. The remaining sample was examined by VPC without any prior removal of meso-diene by preparative scale TLC. The chromatogram (Fig. 6) revealed that the product consisted mainly of trans,trans-diene (93\%) with a small amount of cis,trans-diene (6\%) and of cis,cis-diene (1\%). Since the reaction conditions were clearly too severe, further analysis of the remaining samples was not carried out. 
Stability of trans-1,4-Diphenylhexa-1,5-diene on Alumina.

trans-1,4-Diphenylhexa-1,5-diene, prepared by Grignard coupling of cinnamy1 chloride and supplied by R. P. Lutz, was freshly vacuum distilled $\left(128^{\circ}, 7 \mathrm{~mm}\right)$ and dissolved in heptane to give a solution of $25 \mathrm{mg} /$ m1. This solution was added to activated alumina $\left(650^{\circ}, 4\right.$ hours) to give a ratio of $20 \mathrm{mg}: 1 \mathrm{~g}$. One sample was maintained at room temperature for four hours, another at $60^{\circ}$ for one hour. Isolation of the diene as in previous runs followed by IR and VPC examination showed that the trans-1,4-diphenylhexa-1,5-diene had undergone no change. 


\section{BIBLIOGRAPHY}

1. A. C. Cope and E. M. Hardy, J. Amer. Chem. Soc., 62, 441 (1940).

2. S. J. Rhoads in "Molecular Rearrangement," P. de Mayo, Ed., Vol. I Interscience, New York, N. Y., 1963, Chapter 11.

3. A. C. Cope, C. M. Hofmann, and E. M. Hardy, J. Amer. Chem. Soc., $\underline{63}, 1852$ (1941).

4. H. A. J. Berg, MS Thesis, Portland State University, 1972.

5. W. von E. Doering, V. G. Toscano, and G. H. Beasley, Tetrahedron, 27, 5299 (1971).

6. W. von E. Doering, Zh. Vsesoyuz. Khim. Obshchestva im D. I. MendeIeeva, 7, 308 (1962).

7. G. R. Aldridge and G. W. Murphy, J. Amer. Chem. Soc., 73, 1158 (1951).

8. C. K. Ingold, "Structure and Mechanism in Organic Chemistry," 2nd ed., Corne11 University Press, Ithaca, N. Y., 1969, pp. 867-869.

9. W. von E. Doering and W. R. Roth, Tetrahedron, 18, 67 (1962).

10. E. Vogel and W. Grimme, Angew. Chem., Int. Ed. Engl., 2, 739 (1963).

11. H. P. Koch, J. Chem. Soc., 1111 (1948).

12. R. P. Lutz, S. Berna1, R. J. Boggio, R. O. Harris, and M. W. McNicholas, J. Amer. Chem. Soc., 93, 3985 (1971).

13. J. C. Trebellas, J. R. Olechowski, and H. B. Jonassen, J. Organometal Chem., 6, 412 (1966).

14. P. Heimbach and W. Brenner, Angew. Chem. Int. Ed. Eng1., 6 , 800.(1967).

15. H. Pines and W. O. Haag, J. Amer. Chem. Soc., 82, 2471 (1960).

16. W. O. Haag and H. Pines, ibid., 82, 2488 (1960).

17. R. O. Clinton and S. C. Laskowski, J. Amer. Chem. Soc., 70, 3135 (1948)

18. M. P. Oommen and A. I. Voge1, J. Chem. Soc., 2148 (1930). 


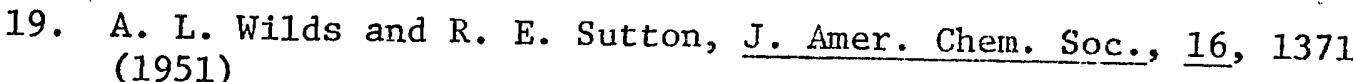

20. L. F. Fieser and M. Fieser, "Reagents for Organic Synthesis," Wiley, New York, N. Y., 1967, p. 1179. 